\title{
Push-pull configuration of high-power MOSFETs for generation of nanosecond pulses for electropermeabilization of cells
}

Davies, Ilan; Merla, C.; Tanori, M.; Zambotti, A.; Mancuso, M.; Bishop, J.; White, M.; Palego, Cristiano; Hancock, Chris

\section{International Journal of Microwave and Wireless Technologies}

\author{
DOI: \\ $10.1017 / \mathrm{S} 1759078719000576$
}

Published: 30/09/2019

Peer reviewed version

Cyswllt i'r cyhoeddiad / Link to publication

Dyfyniad o'r fersiwn a gyhoeddwyd / Citation for published version (APA):

Davies, I., Merla, C., Tanori, M., Zambotti, A., Mancuso, M., Bishop, J., White, M., Palego, C., \& Hancock, C. (2019). Push-pull configuration of high-power MOSFETs for generation of nanosecond pulses for electropermeabilization of cells. International Journal of Microwave and Wireless Technologies, 11(7), 645-657. https://doi.org/10.1017/S1759078719000576

\footnotetext{
Hawliau Cyffredinol / General rights

Copyright and moral rights for the publications made accessible in the public portal are retained by the authors and/or other copyright owners and it is a condition of accessing publications that users recognise and abide by the legal requirements associated with these rights. study or research.

- Users may download and print one copy of any publication from the public portal for the purpose of private

- You may not further distribute the material or use it for any profit-making activity or commercial gain

- You may freely distribute the URL identifying the publication in the public portal?
}

Take down policy

If you believe that this document breaches copyright please contact us providing details, and we will remove access to the work immediately and investigate your claim. 


\title{
Push-Pull Configuration of High Power MOSFETs for Generation of Nanosecond Pulses for Electropermeabilization of Cells
}

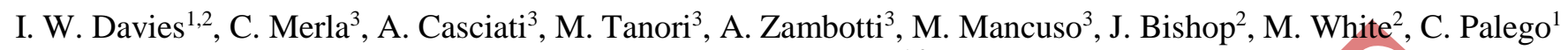 \\ and C. P. Hancock ${ }^{1,2}$
}

${ }^{1}$ School of Computer Science and Electronic Engineering, University of Bangor, Bangor, United Kingdom.

\author{
${ }^{2}$ Creo Medical, Bath, United Kingdom.
}

${ }^{3}$ Division of Health Protection Technologies, ENEA-Casaccia, Rome 00123, Italy.

\begin{abstract}
A power MOSFET-based push-pull configuration nanosecond-pulse generator has been designed, constructed, and characterized to permeabilize cells for biological and medical applications. The generator can deliver pulses with durations ranging from 80ns up to $1 \mu$ s and pulse amplitudes up to $1.4 \mathrm{kV}$. The unit has been tested for in-vitro experiments on a medulloblastoma cell line.
\end{abstract}

Following the exposure of cells to 100ns, 200ns and 300ns electric field pulses, permeabilization tests were carried out, and viability tests were conducted to verify the performance of the generator. The maximum temperature rise of the biological load was also calculated based on Joule heating energy conservation and experimental validation.

Our results indicate that the developed device has good capabilities to achieve well controlled electro-manipulation invitro.

Keywords: Medical and Biological Effects, Circuit Design and Applications, EM Field Theory and Numerical Techniques, Passive Components and Circuits, Si-based Devices and IC Technologies

\section{INTRODUCTION AND BACKGROUND}

Classical electroporation implies the application of controlled pulsed direct current / electric field in the milli-to-micro second $(\mathrm{ms}-\mu \mathrm{s})$ regime to cells and tissues. The applied electric field pulses are known to result in increased plasma membrane permeabilization thus enabling the introduction of small molecules and modulation of cell viability [1-6]. Using suitable protocols, electroporation has been successfully exploited as a medical ablation technique intraoperatively, laparoscopically and percutaneously [1-6].

Nanosecond electroporation (using high-voltage pulses with a width of a few nanoseconds up to a few hundred nanoseconds) is a further development of the classical electroporation. Literature suggests it has additional potentials for cell manipulation and control of cell physiology [3]. Nanosecondpulse effects include: calcium $\left(\mathrm{Ca}^{++}\right)$release, ion channels activation and apoptosis induction [3, 7-10].
Ablation of cancer tissue using nanosecond pulsed electric fields has been demonstrated. In some cases this technique resulted in complete tumour remission [11-17]. Furthermore, this treatment strategy stimulates the immune system thus determining an immunogenic cell death. The activation of the immune system prevented tumour regrowth when a second cancer cell injection was conducted in xenograft in-vivo models $[12-15]$.

Nanosecond pulsed electric field could be additionally interesting for the treatment of cancer stem cells (CSCs) [18]. Primary cancers, such as Medulloblastoma (MB), are extremely challenging to treat with conventional therapies (i.e. chemotherapy and radiotherapy) and this has been linked to the presence of CSCs [1, 19-21]. Unlike normal cancer cells, CSCs possess stem-cell like properties and the ability to recover from cytotoxicity, leading to tumour initiation, invasion and relapse $[1,22-23]$.

In 2014, approximately 11,000 people were diagnosed with primary brain tumour in the UK with a median survival rate of 15 months and a 5-year survival rate of $4 \%$ [19-20]. Therefore, there is a crucial need for an alternative therapeutic treatment to eradicate or selectively neutralise CSCs, which may well require the development of a compact low-cost nanosecond pulsed electric field generator.

Advancement of semiconductor technology, particularly Silicon Carbide ( $\mathrm{SiC}$ ) has made possible to develop a costeffective $(<£ 350)$ compact $(99 \mathrm{~mm} \times 254 \mathrm{~mm} \times 244 \mathrm{~mm})$ nanosecond pulsed electric field generator which utilizes offthe-shelf components to match the performance once achieved by much bulkier and more expensive technologies [24-30]. In this paper, a new generator is presented (Section II) and its realization described together with experimental characterization (Section III). In-vitro investigation of MB cell line permeabilization and viability were carried out to test the performance of the new generator in operational conditions (Section III). Specifically, a D283 MB cell line rich in MB $\mathrm{CSCs}$ in a $50 \Omega$ buffer solution [31] was treated using an electric 
field amplitude of $1 \mathrm{MV} / \mathrm{m}$, and pulse widths extending from $100 \mathrm{~ns}$ to $300 \mathrm{~ns}$.

\section{MATERIALS AND METHODS}

Micro-millisecond pulse generators capable of producing electric field strengths up to $100 \mathrm{kV} / \mathrm{mm}$ are available commercially [24-26]. In comparison to micro-millisecond pulse generators, there are significantly fewer high-voltage nanosecond pulsed electric field generators available commercially [27-30]. In recent years there have been numerous developments of nanosecond high-voltage pulsed electric field generators within the research field, with over 500 citations since 2017 on Google Scholar [32].

Traditionally, coaxial transmission line-based implementations, such as Blumlein, in correlation with spark-gap, Marx bank or diode opening switch techniques have been used to generate high-voltage nanosecond-pulses [33-36]. These techniques can produce pulses with very high amplitude (voltages in excess of $5 \mathrm{kV}$ ), short durations (widths varying from $1 \mathrm{~ns}$ to $300 \mathrm{~ns}$ ), with fast rise time $(<2 \mathrm{~ns})$. Yet there is complexity associated with these designs.

In recent years the use of power modules, such as Metal Oxide Semiconductor Field Effect Transistors (MOSFETs), InsulatedGate Bipolar Transistors (IGBTs) and Bipolar Junction Transistors (BJTs) has been demonstrated in literature as a method to produce high-voltage nanosecond-pulses in various pulse generator designs. Designs include: MOSFET or IGBT stacking (series, parallel or crowbar design), solid state Marx bank, capacitor array methodology etc or a combination of these methodologies [33-38]. Table 1 summarises the advantages and disadvantages of the various technologies in producing nanosecond electric pulses.

The requirement for these developed nanosecond electric pulse generators is to produce pulses with duration of $100 \mathrm{~ns}$ to $300 \mathrm{~ns}$ with amplitudes in excess of $1 \mathrm{kV}$, into a $50 \Omega$ load, whilst being cost-effective. From Table 1, it is concluded that utilizing MOSFETs, IGBTS or BJTs is the practical choice to deliver the nanosecond-pulse generator requirement.

With the latest advancements in semiconductor and $\mathrm{SiC}$ material technology, recent power components can deliver voltage pulses in excess of $1.7 \mathrm{kV}$ with pulse widths in the submicrosecond regime. Comparing commercially available MOSFETs, IGBTs and BJTs, MOSFET technology is the most suited semiconductor technology for this nanosecond electric pulse generator design. MOSFETs unlike IGBTs and BJTs are cheaper and can produce pulses within the $100 \mathrm{~ns}$ to $300 \mathrm{~ns}$ regime with transition times (rise and fall time) faster than $100 \mathrm{~ns}$, although all three have breakdown voltages (collectoremitter or drain-source voltage) in excess of $1 \mathrm{kV}$. The comparison between MOSFET, IGBT and BJT is summarized in Table 2 when comparing a typical commercial component available on the market (uk.rs-online.com).
Table 1. Summary of the comparative performance between the various techniques for producing nanosecond electric pulses.

\begin{tabular}{|c|c|c|}
\hline Technique & Advantages & Disadvantages \\
\hline Capacitor discharge & Simple and inexpensive & $\begin{array}{l}\text { Poor flexibility and } \\
\text { control of parameters } \\
\text { Slow capacitive } \\
\text { discharge fall time }\end{array}$ \\
\hline Transmission line & $\begin{array}{l}\text { High-voltage and current } \\
\text { pulse } \\
\text { Possible variable } \\
\text { duration and polarity of } \\
\text { pulse }\end{array}$ & $\begin{array}{l}\text { Complex switching } \\
\text { element } \\
\text { Impedance matching } \\
\text { required } \\
\text { Pulse width } \\
\text { inflexibility (limited } \\
\text { to transmission line) }\end{array}$ \\
\hline Spark-gap & $\begin{array}{l}\text { High-voltages and } \\
\text { current pulse. } \\
\text { Fast repetition frec } \\
\text { and pulse width }\end{array}$ & $\begin{array}{l}\text { Complex switching } \\
\text { and low control of } \\
\text { pulse parameters eg. } \\
\text { pulse width and } \\
\text { amplitude }\end{array}$ \\
\hline $\begin{array}{l}\text { Semiconductors } \\
\text { (MOSFETs, IG } \\
\text { and BJTs) }\end{array}$ & $\begin{array}{l}\text { Simple control system } \\
\text { Inexpensive } \\
\text { Good control and } \\
\text { flexibility in pulse } \\
\text { parameters } \\
\text { Square pulse }\end{array}$ & $\begin{array}{l}\text { Low pulse amplitude } \\
\left(\sim 2 \mathrm{kV}_{\max }\right) \\
\text { Limited rise and fall } \\
\text { times }\end{array}$ \\
\hline
\end{tabular}

These features, in Table 2, make MOSFETs configured in a push-pull configuration an attractive option for the design of a compact and cost-efficient nanosecond pulsed electric field generator that meets the design requirement. Implementing the other techniques of producing nanosecond electric pulses, highlighted in Table 1 and 2, would be significantly less cost effective and efficient with the additional complexity in their design.

Table 2. Comparing MOSFET, IGBT and BJT typical parameters with existing product.

\begin{tabular}{|l|l|l|l|}
\hline Technology & MOSFET & IGBT & BJT \\
\hline Component & C2M1000170D & GT40WR21 & TSC8502D \\
\hline Datasheet & {$[39]$} & {$[40]$} & {$[41]$} \\
\hline Breakdown voltage & $1700 \mathrm{~V}$ & $1800 \mathrm{~V}$ & 1050 \\
\hline Rise time & $10.5 \mathrm{~ns}$ & $400 \mathrm{~ns}$ & $1 \mu \mathrm{s}$ \\
\hline Fall time & $60 \mathrm{~ns}$ & $150 \mathrm{~ns}$ & $1.2 \mu \mathrm{s}$ \\
\hline Cost per Unit & $£ 4.07$ & $£ 4.56$ & $£ 0.153$ \\
\hline
\end{tabular}

In the following work, our modular design is presented along with its numerical and experimental characterization. The biological results obtained using the generator indicate that this compact, cost-efficient approach has a strong potential for clinical application. 


\section{A. Nanosecond-pulse generator modular design}

The modular design is based on a push-pull switch configuration of two Wolfspeed's C2M1000170D SiC MOSFET (S1 and S2 in Figure 1) [39], that are directly driven by Toshiba's TLP352 photocoupler (DR1 and DR2 in Figure 1a) [42]. The ability of the design to generate the required pulses is dependent upon the switching times and maximum drain-source voltage of the MOSFETs. The SiC MOSFETs are voltage-controlled semiconductor devices that efficiently store charge in their minority carrier region resulting in very rapid turn on $\left(\mathrm{t}_{\mathrm{r}}\right)$ and turn-off $\left(\mathrm{t}_{\mathrm{f}}\right)$ times.

For this application it was important to choose a power MOSFET with a maximum drain-source voltage $>1 \mathrm{kV}$ and total switching times below $100 \mathrm{~ns}$ (the actual values are: $\mathrm{t}_{\mathrm{r}}=$ $10.5 \mathrm{~ns}$ and $t_{\mathrm{f}}=60 \mathrm{~ns}$ [39]) to generate an electrical pulse of 100 ns duration with amplitudes in excess of $1 \mathrm{kV}$, into a $50 \Omega$ load. An n-channel enhancement type MOSFET device was used, where a positive gate-source voltage $\left(\mathrm{V}_{\mathrm{gs}}\right)$ opens up the channel to control the drain current (iD). The transconductance characteristic ( $i_{D}$ as a function of $V_{g s}$ ) was also considered carefully when choosing the most appropriate MOSFET to use.

Selecting a push-pull configuration of MOSFETs over the conventional transmission line-based design or other alternatives for generating nanoseconds electric pulses provides numerous advantages (Table 1 and 2). In addition for being a compact and cost-effective, this design provides a more controllable method of delivering various nanosecond electric pulses, such as: pulse widths, repetition frequency, number of pulses and pulse amplitude, in comparison to other techniques mentioned. These aspects of using power MOSFETs are advantageous for the usage of a well-controlled electromanipulation technique while supporting further nanosecondpulse-based applications and research in biology, medicine and/or biotechnology.

An input capacitance $\left(\mathrm{C}_{\text {input }}\right)$ of around $200 \mathrm{pF}$ exists between the gate and the channel [42-45]. This capacitance must be charged when the device is turned on and discharged when it is turned off. The charge and discharge times must be as short as possible. A gate driver is therefore necessary to provide enough current to charge this capacitance for the necessary $\mathrm{V}_{\mathrm{gs}}$ to appear across the gate-source terminals, to enable the required $\mathrm{i}_{\mathrm{D}}$ flow. The total gate capacitance $\left(\mathrm{C}_{\text {gate }}\right)$ is made up of the gatesource capacitance $\left(\mathrm{C}_{\mathrm{gs}}\right)$ and the gate-drain capacitance $\left(\mathrm{C}_{\mathrm{gd}}\right)$ as the current required to charge up this capacitance $\left(i_{c}\right)$ is given:

$$
\begin{aligned}
C_{\text {gate }}=C_{\text {input }} & =\left(C_{g s}+C_{g d}\left(1+g_{m} R_{L}\right)\right) \\
i_{c} & =C_{\text {gate }} \frac{d V_{g s}}{d t}
\end{aligned}
$$

where $\mathrm{g}_{\mathrm{m}}$ is the transconductance $\left(\frac{d i_{D}}{d V_{g s}}\right)$ of the MOSFET and $\mathrm{R}_{\mathrm{L}}$ is the load impedance. In this work $\mathrm{R}_{\mathrm{L}}$ is $50 \Omega$, representing the standard commercial impedance of cables and connectors necessary to link the generator to the biological load.

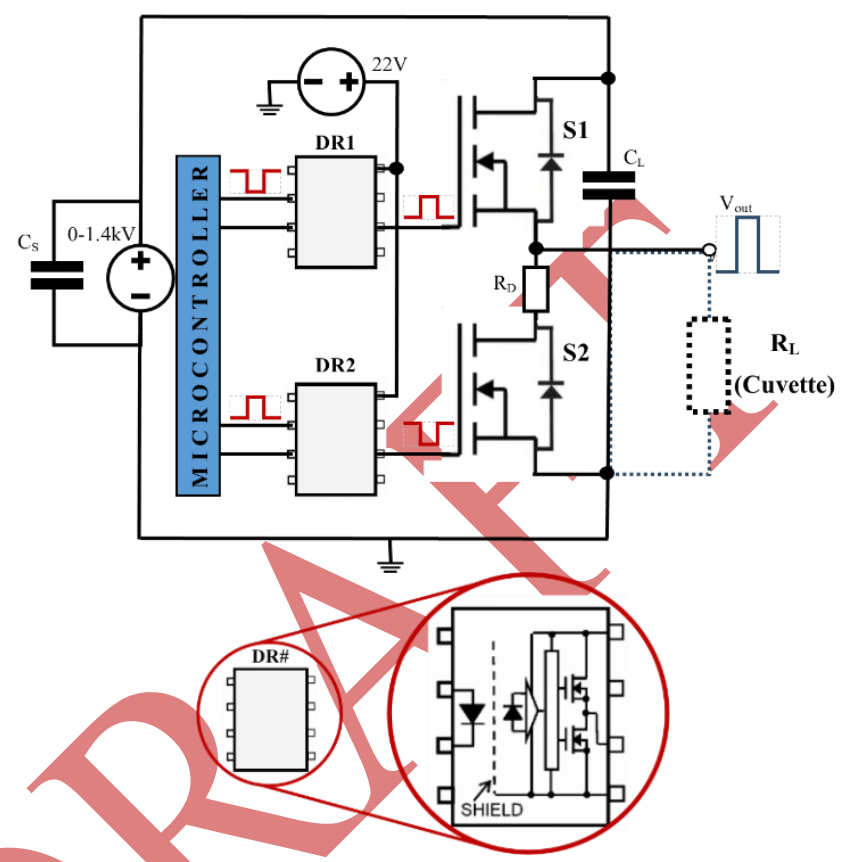

(a)
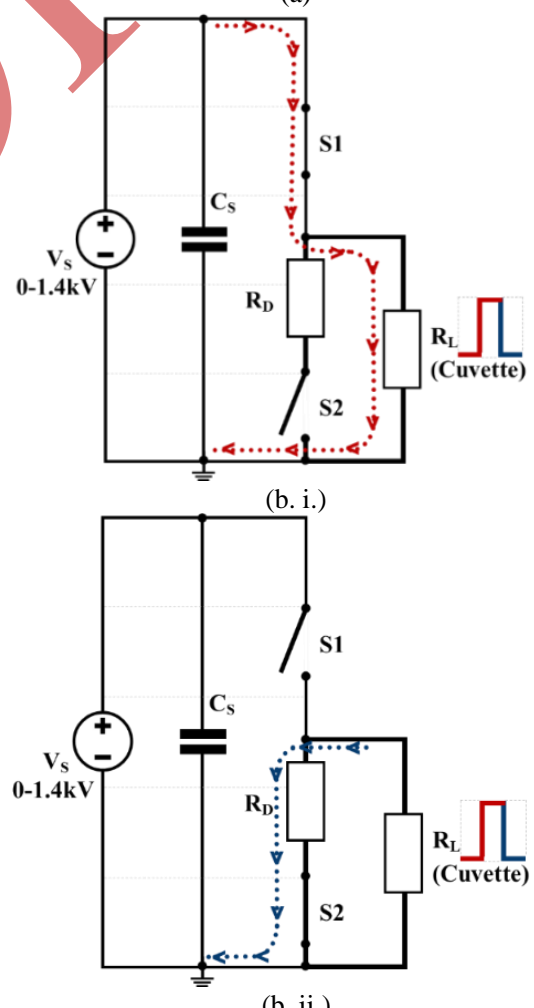

(b. ii.)

Figure 1. The basic modular design of the developed nanosecond generator (a) simplified schematic. Note: DR1 and DR2 circuits have been simplified for graphical clarity. (b) simplified equivalent circuit of the generator showing the current path when: i. S1 is closed and S2 open; ii. S1 is open and $\mathrm{S} 2$ is closed. 
The selected opto-couplers (DR1 and DR2) operate as a gate driver, which provides the necessary current $\left(2.5 \mathrm{~A}_{\max }\right)$ to charge and discharge the $\mathrm{C}_{\mathrm{gs}}$ and $\mathrm{C}_{\mathrm{gd}}$ [43-45].

The power MOSFET was chosen based on the fastest possible switching times, which in turn are determined by the charging and discharging times of $\mathrm{C}_{\mathrm{gs}}$ and $\mathrm{C}_{\mathrm{gd}}$ (mentioned above).

If a single MOSFET is used to generate the sub-microsecond high-voltage pulses at a load, then the gate-source capacitance of the MOSFET has to be charged and discharged resulting in unacceptably long switching times. This is particularly true for the discharge of the input capacitance necessary to switch the pulse off. The fall-time of the pulse is dictated by the discharge time constant of the gate-source capacitance of the MOSFET and is dependent on the gate-source capacitance and load resistance $\left(t_{f}=\tau=C_{g s} R_{L}\right)$.

To overcome this problem two MOSFETs can be used in a push-pull configuration, as shown in Figure 1a. This switching topology means that when the high-side MOSFET (S1) is open ('off') the low-side MOSFET (S2) is closed ('on'), and vice versa. The relationship between the two-gate driver signals to the MOSFET switches is synchronized and complementary to one another.

The simplified equivalent circuit of the nanosecond generator is illustrated in Figure 1b.i and ii. When S1 (the high-side MOSFET) is turned on, a high-voltage is applied to the load. The current flow (red dotted line), for this action, is shown in Figure 1b.i. In addition, applying high-voltage to the load, S1 determines the pulse duration (width) and rise time at the load.

When S1 is turned off, S2 is turned on. This creates a second path for the current to flow (blue dotted line), Figure 1b.ii. The switching of S2 creates a low impedance path, which allows the high-voltage pulse delivered at the load to discharge to ground. Thus, $\mathrm{S} 2$ controls the pulse fall time at the load.

The $\mathrm{R}_{\mathrm{D}}$ resistor in Figure 1 and 3 protects the circuit from a failure / open control signal, ensuring a pull-down of the gate signal of the high-side MOSFET (S1), turning S1 off, and that the pulse seen at the load is grounded $(0 \mathrm{~V})$ and not floating (> $0 \mathrm{~V}) . \mathrm{R}_{3}$ and $\mathrm{R}_{5}$, in Figure 3, provide similar modality to $\mathrm{R}_{\mathrm{D}}$, but they ensure pull-down of the gate driving signals to $S 1$ and $S 2$ from there respected photocoupler (DR1 and DR2).

Implementing a push-pull configuration results in a faster falltime than is possible for a single MOSFET implementation and leads to a square shaped, symmetrical pulsed electric field at the load, Figure 2.

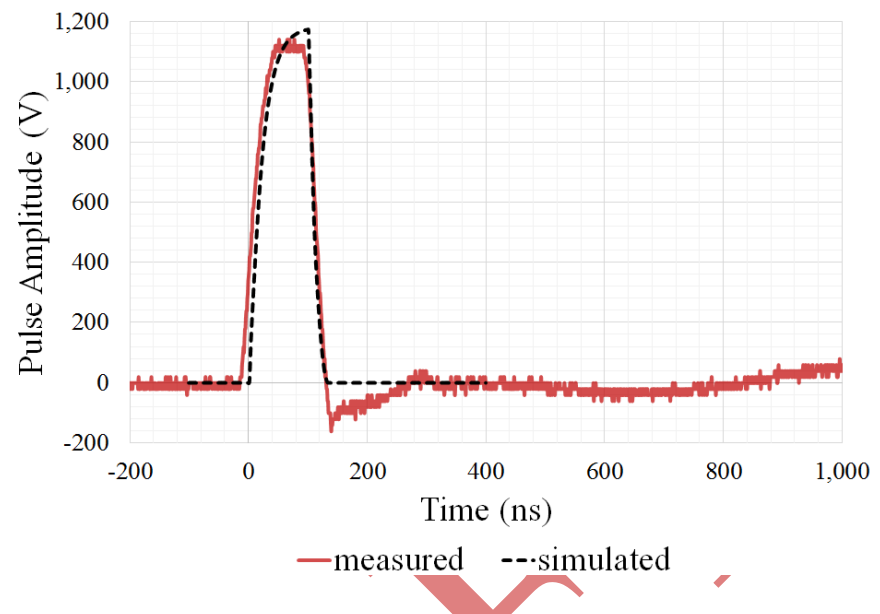

Figure 2. 100ns pulse obtained by LTSpice simulation (black dashed line) and measured from the developed generator (red solid curve) with a $50 \Omega$ load.

It is imperative that both S1 and S2 are not switched 'on' simultaneously. In such an event, no pulse would be measured across the load as the voltage from the power supply would be grounded through a direct low impedance path to ground. This circumstance could result in shorting of the power supply and a potential temperature rise or breakdown of MOSFETs due to the high-voltage swing $(1.4 \mathrm{kV})$ in a low-impedance pattern.

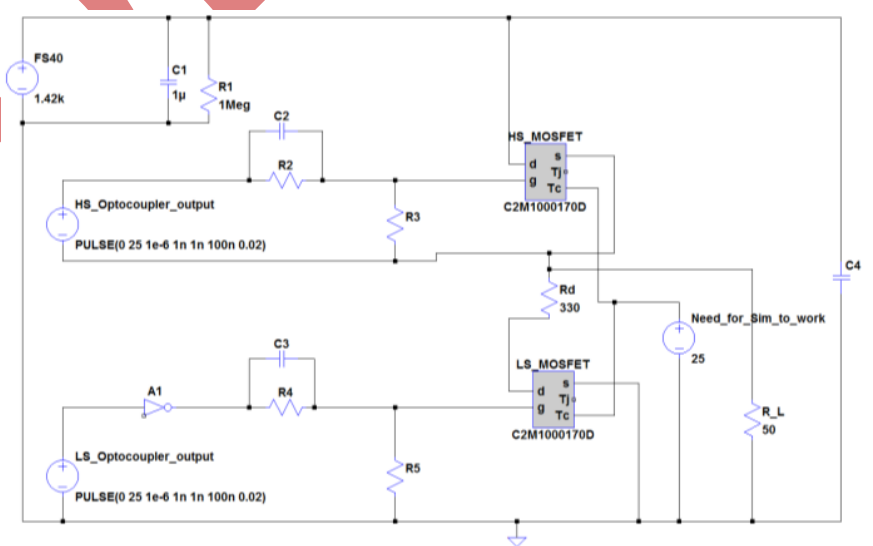

Figure 3. LTSpice simulation circuit diagram, with spice model of Wolfspeed's MOSFETs [43].

\section{B. Simulated vs measured performances}

Following the development of the nanosecond pulsed electric field generator, a LTSpice model of the modular design was developed as shown in Figure 3. The simulated design utilised the PSpice model of the C2M1000170D SiC MOSFET obtained from Wolfspeed's website [46].

Figure 4a demonstrates that the actual generator performance exceeds LTSpice simulation. It can be seen that the measured pulse across a $50 \Omega$ resistive load, in practice, is more symmetrical and has a faster risetime than the simulated pulse. This could be the result of a higher gate current in practice, thus, resulting in faster charging of the internal gate capacitance. 
Figure 4.bi and 4.bii show good agreement with (1) and (2) analytical description of the MOSFET switching and driving process.

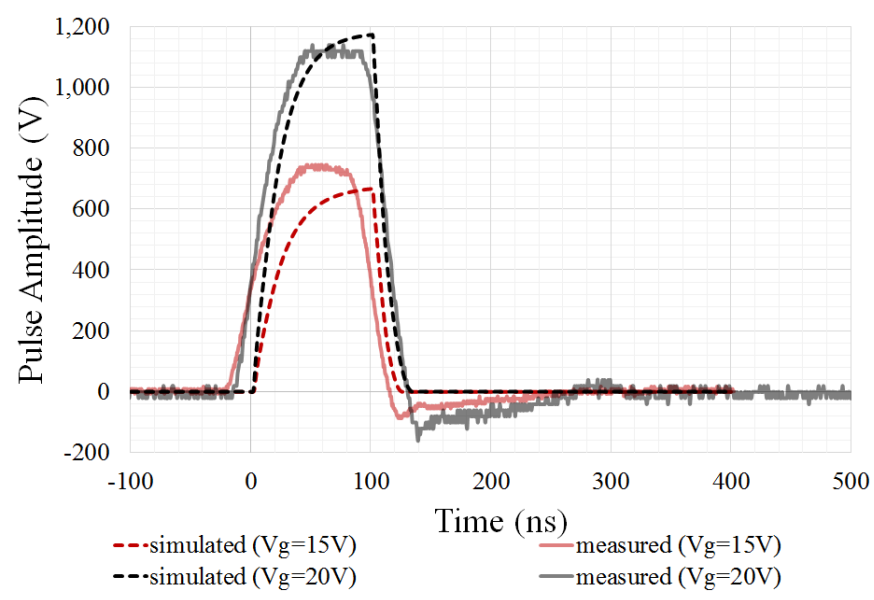

(a)
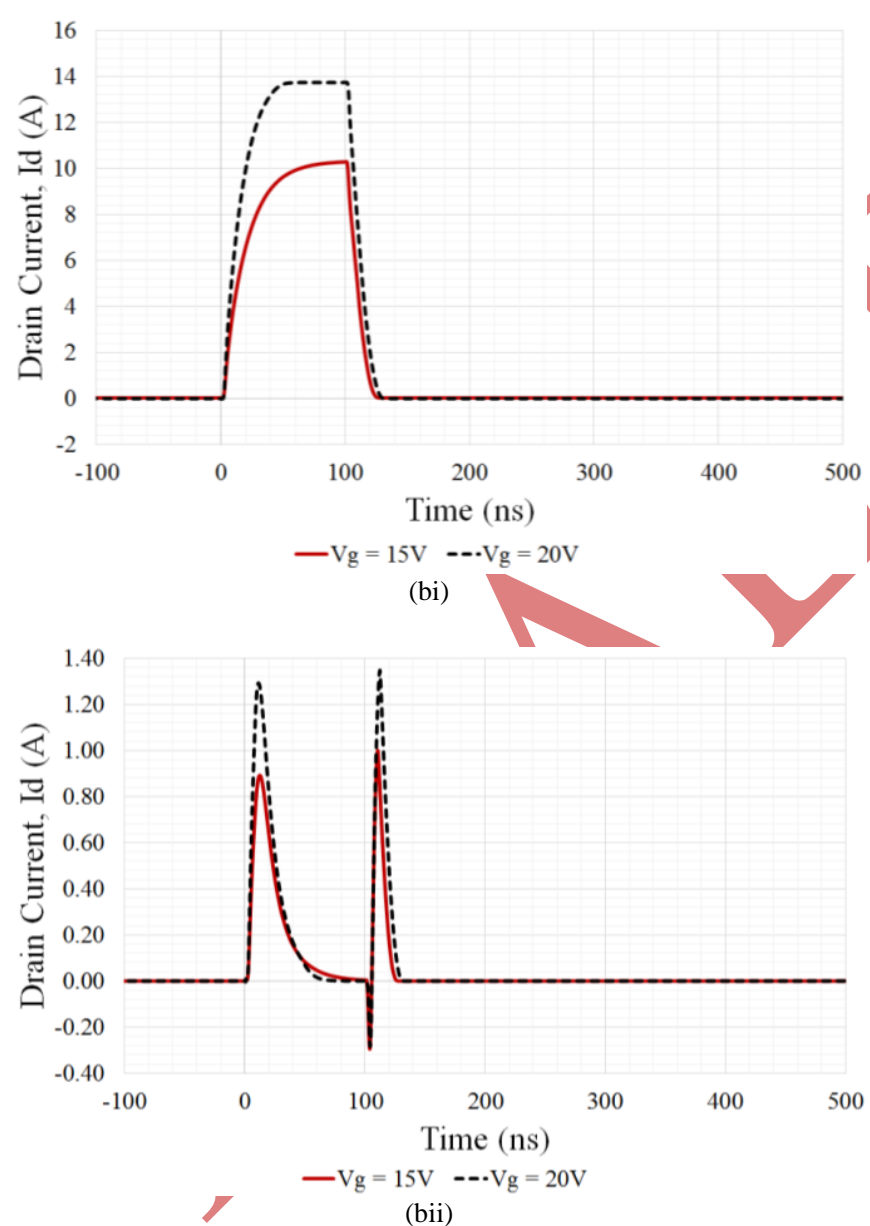

Figure 4 (a) Measured (solid lines) vs LTSpice simulation results (dashed lines) for $100 \mathrm{~ns}$ pulse on a $50 \Omega$ load, with various gate voltages $(15 \mathrm{~V}$ (red) and $20 \mathrm{~V}$ (black)). (b) drain current during switching on the (i) high-side MOSFET and (ii) low-side MOSFET in LTSpice simulation with 15V (solid red line) and 20V (black dashed line) gate voltages.
Table 3 shows the bill of material for the key components used in the generator. The overall cost for the bill of material for the generator was less than $£ 350$. The majority of the cost is the enclosure and the high-voltage supply (FS40).

Table 3. Bill of material of the generator's critical components (at time of write-up).

\begin{tabular}{|c|c|c|c|}
\hline Component & Distributor & $\begin{array}{l}\text { Cost per } \\
\text { Unit }(\mathfrak{f})\end{array}$ & Quantity \\
\hline $\begin{array}{l}\text { C2M1000170D SiC } \\
\text { N-Channel MOSFET }\end{array}$ & $\begin{array}{l}\text { RS } \\
\text { Comp }\end{array}$ & & 2 \\
\hline $\begin{array}{l}\text { Toshiba, TLP352 } \\
\text { Opto-coupler }\end{array}$ & $\begin{array}{l}\mathrm{RS} \\
\text { Components }\end{array}$ & 0.98 & \\
\hline LT1713 Comparator & & 3.93 & 3 \\
\hline $\begin{array}{l}\text { XPPower FS40 High- } \\
\text { voltage Converter }\end{array}$ & $\begin{array}{l}\text { RS } \\
\text { Components }\end{array}$ & 4 & 1 \\
\hline $\begin{array}{l}\text { Enclosure }(99 \mathrm{~mm} \text { x } \\
254 \mathrm{~mm} \text { x } 244 \mathrm{~mm})\end{array}$ & & 99.77 & 1 \\
\hline
\end{tabular}

The high-voltage supply (FS40) is an essential component and was limited to producing a voltage output of $1.4 \mathrm{kV}$. The source was capped to $1.4 \mathrm{kV}$ to ensure the voltage supplied to the MOSFET drain pin does not exceed it maximum drain-source breakdown voltage $\left(\mathrm{V}_{\mathrm{DS} \max }=1.7 \mathrm{kV}\right)$. The FS40 is a compact $(57.15 \mathrm{~mm} \times 28.5 \mathrm{~mm} \times 12.7 \mathrm{~mm})$ proportional DC to highvoltage DC source which provides isolation from the highvoltage $(0 \mathrm{~V}-1.4 \mathrm{kV})$ output from its low voltage input $(0 \mathrm{~V}$ 5V) [47].

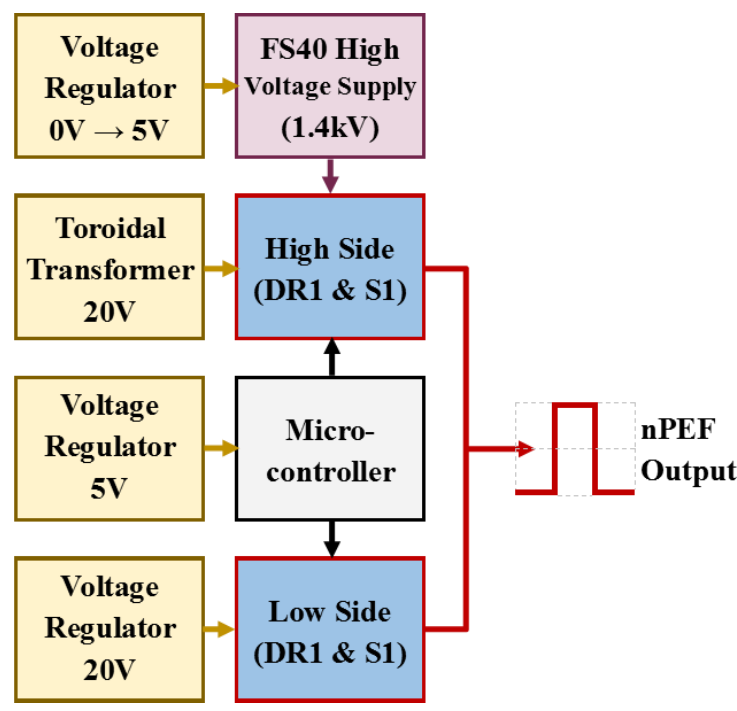

Figure 5. Design block diagram of Veroboard modules.

The generator dimensions is limited to the enclosure size (99mm x 254mm x 244mm). In future adaptations the nanosecond electric pulse generator can be smaller in size. Within the current enclosure there are unoccupied areas. Presently, the circuits are built on Veroboard, with each 
subsection module of the design occupying a single board, as illustrated in Figure 5. Integrating the individual Veroboard subsections onto a single printed circuit board would significantly reduce the area occupation of the current enclosure, reducing the generator's size and cost in future implementations.

\section{Nanosecond pulse verification and validation.}

A Verification and Validation $(\mathrm{V} \& \mathrm{~V})$ process was undertaken to check if the system meets the electrical specifications outlined and also to evaluate the intended purpose of biological cells nanoporation.

The electrical specifications outlined was to generate pulsed electric fields with a pulse duration from $100 \mathrm{~ns}$ to $300 \mathrm{~ns}$ with voltage amplitudes in excess of $1 \mathrm{kV}$, with a repetition frequency ranging from $1 \mathrm{~Hz}$ to $50 \mathrm{~Hz}$, on a $50 \Omega$ load.

Table 4. Generator characteristics.

\begin{tabular}{|l|c|l|}
\hline Parameters & Range & Comment \\
\hline Frequency (Hz) & $1-50$ & Pulse repetition frequency \\
\hline $\begin{array}{l}\text { Pulse Width } \\
(\mathrm{ns})\end{array}$ & $80-1000$ & $\begin{array}{l}\text { Increments of 10ns (between 80ns-400ns) } \\
\text { and 20ns (between 400ns-1us) }\end{array}$ \\
\hline Burst & $1-$ & Number of pulses generated successively \\
\hline $\begin{array}{l}\text { Pulse } \\
\text { Amplitude (V) }\end{array}$ & $250-1400$ & $\begin{array}{l}\text { Can be varied by rotary potentiometer dial } \\
\text { on the generators front panel }\end{array}$ \\
\hline
\end{tabular}

An 'Arduino Uno' microprocessor with a LCD keypad shield provides an user friendly user interface in addition to providing precise control and a wide range of pulse profiles to be generated (see Table 4). In further implementations the Arduino could be replaced by a single microcontroller chip.

Figure $6 a$ indicates that the pulse amplitude is unaffected throughout its operating repetition frequencies of $1 \mathrm{~Hz}$ to $50 \mathrm{~Hz}$ (result obtained with a $50 \Omega$ resistor load and a pulse width of 100ns). Furthermore, Figure $6 \mathrm{~b}$ also suggests that the generators performance is optimized to the intended specifications as amplitudes in excess of $1 \mathrm{kV}$ are generated in the pulse width range from $100 \mathrm{~ns}$ to $300 \mathrm{~ns}$ (result obtained with a $50 \Omega$ resistor load and $50 \mathrm{~Hz}$ repetition frequency).
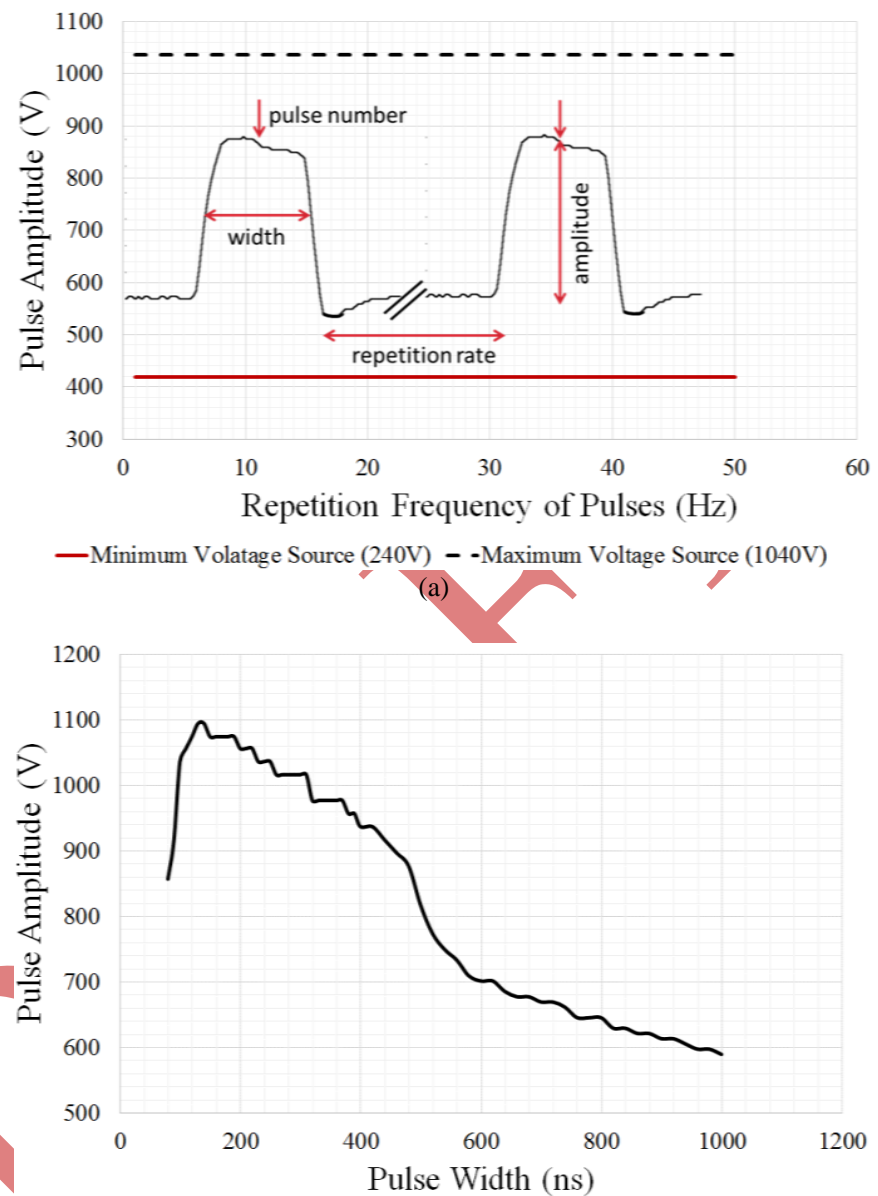

(b)

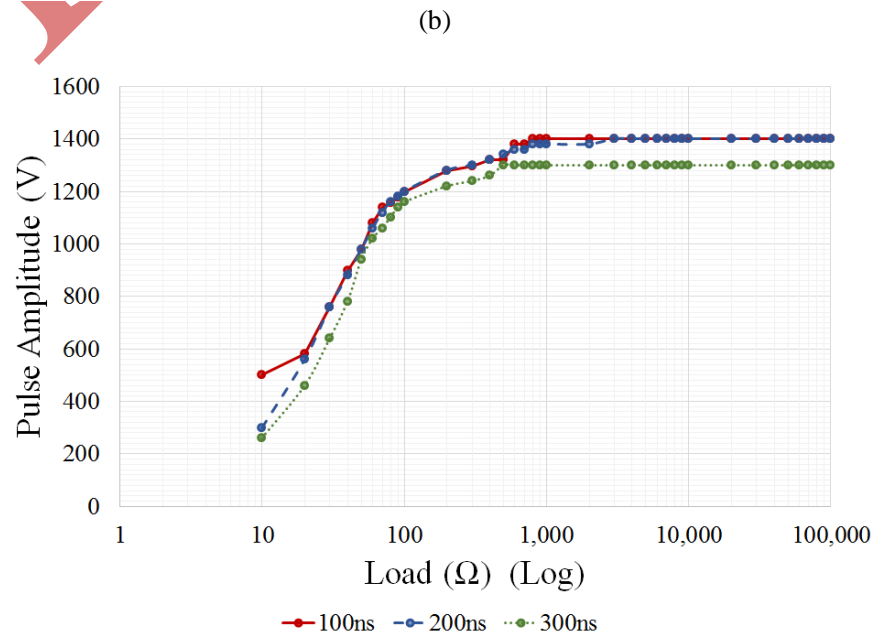

(c)

Figure 6. Measured characteristics of the generator pulse amplitude: (a) as a function of the repetition frequency $1 \mathrm{~Hz}$ to $50 \mathrm{~Hz}$ (with pulse widths of $100 \mathrm{~ns}$ ). (b) as a function of pulse width (at $50 \mathrm{~Hz}$ repetition frequency). (c) as a function of load resistance for three different pulse widths (100ns, 200ns and 300ns).

On the other hand, Figure $6 \mathrm{c}$ indicates that the nanosecond pulsed electric field generator is impedance sensitive. With a load below $500 \Omega$, the pulse amplitude decreases. This decrease appears linear (on a log scale) with a load equal or less than $100 \Omega$. This effect is due to the voltage source. Like most voltage sources they are mismatched to a low impedance or 
short-circuited load. Additionally, Figure 6c suggests that the power source used has an internal impedance of $\sim 30 \Omega$ as a load of $\sim 30 \Omega$ experiences half $(700 \mathrm{~V})$ of the voltage generated $(1400 \mathrm{~V})$, behaving as a voltage divider.

The load curve was obtained by loading the generator with various resistive loads of low inductance (planar resistor) and measuring the pulse amplitude observed with the particular load. Reasoning for a $50 \Omega$ load is explained in the next section, II D.

\section{Biological $50 \Omega$ load}

Due to the fast rise and fall times of the pulses, it was necessary to consider transmission line with a characteristic impedance of $50 \Omega$. Cables and connector were therefore used for the cuvette housing unit that have a characteristic impedance of $50 \Omega$. Therefore, it was necessary to match the biological load $\left(\mathrm{R}_{\mathrm{L}}\right)$ to $50 \Omega$. In practice, D283 cell-line suspended in standard culture medium known as Modified Eagle Medium (MEM) has an estimated impedance of $\sim 10 \Omega$ due to the high conductivity of the suspending medium of around $1.5 \mathrm{~S} / \mathrm{m}[2,48]$. Impedance mismatch minimization between the generator, cuvette holder and the load (cuvette filled with cell solution) is imperative to guarantee the generator can deliver nanosecond electric pulses in excess of $1 \mathrm{kV}$ amplitude.

To get $50 \Omega$ impedance matching within the whole in-vitro setup, when the generator is connected to a biological load, the cells were suspended in an artificial buffer solution that is able to mimic a pure resistive $50 \Omega$ load. Additionally, a $50 \Omega$ load is advantageous to minimise mismatch with other microwave and electronics, such as: components, connections and devices (e.g. oscilloscopes, voltage and current probes, attenuators, dividers)

$100 \mathrm{~mL}$ of our artificial buffer solution consists of $20 \mathrm{~mL}$ of phosphate buffer saline (PBS), $80 \mathrm{~mL}$ of distilled water and $8.2 \mathrm{~g}$ of sucrose to counteract osmotic pressures of the cells because of the distilled water. The artificial $50 \Omega$ buffer solution has a conductivity of $0.3 \mathrm{~S} / \mathrm{m}$ [49].

\section{E. In-vitro investigation set-up}

High field exposure of D283 MB cell line to high 100ns to $300 \mathrm{~ns}$ pulses were conducted by a Bio-rads commercially available $0.1 \mathrm{~cm}$ gap, $100 \mu \mathrm{L} \mathrm{EP}$ cuvettes $\left(1 \mathrm{~mm} \times 55 \mathrm{~mm}^{2}\right)$ [50]. The cuvette housing unit in Figure 7 a was designed by ENEA and provides a direct and easy (standard $50 \Omega$ connector) connection between the cuvette and the pulse generator (Figure $7 \mathrm{~b}$ and $\mathrm{c})$.

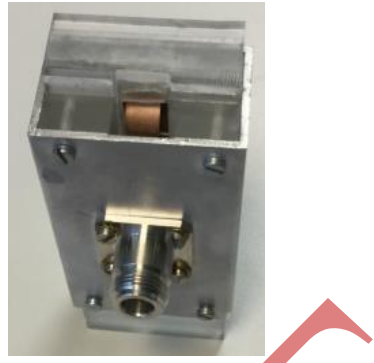

(a)
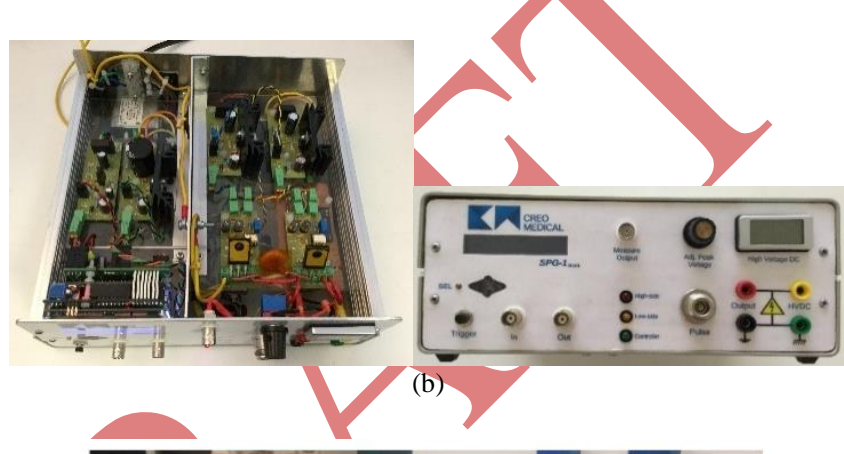

(b)

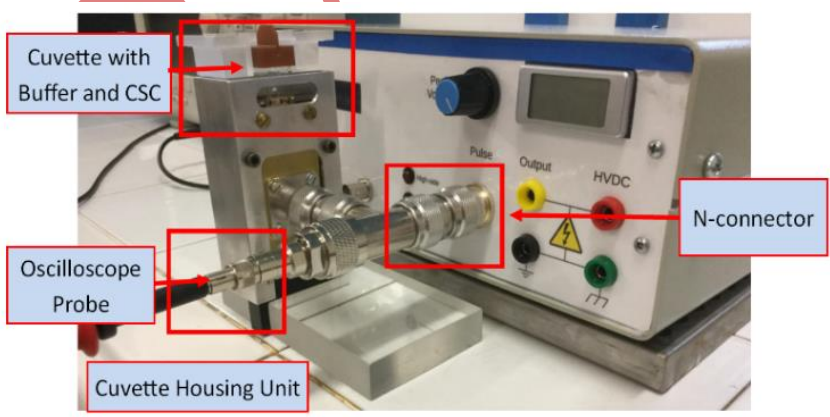

(c)

Figure 7 The in-vitro investigation set-up (a) ENEA's cuvette housing unit. (b) the nanosecond-pulse electic field generator (c) the global arrangement of the initial bench study to investigate the performance of the nanosecondpulse generator on D283 MB cell line.

Furthermore, the cuvette housing units allows real-time monitoring of the applied voltage pulse via an oscilloscope to assess electric field delivered to cells. The electric field between the cuvette electrodes (that form a capacitance loaded by biological solution) has a very homogenous distribution as already suggested in $[2,51]$ by numerical simulations, and it can be well estimated as the ratio between the applied voltage over the electrode distance.

The complete setup for preliminary study of the D283 cell line is shown in Figure 7c. The results of permeabilization and viability tests are discussed in the next section.

\section{RESULT AND ANALYSIS}

\section{A. Nanosecond-pulses delivered to the D283 cell line}

The first in-vitro experiments aimed at characterizing the generator in terms of the real pulse waveform delivered to D283 cells, rather than to a $50 \Omega$ resistor (Figs. 2, 4 and 5). 
Experiments were performed using the electroporation cuvettes filled with buffer solution containing cells (D283 cell line is mixed population of differentiated and stem like cells as reported in [49]). The voltage pulse/pulsed waveforms where captured in real time via a Tektronix TDS5054B-NV Oscilloscope [52] and a high-voltage probe (LeCory PPE 5kV [53]).

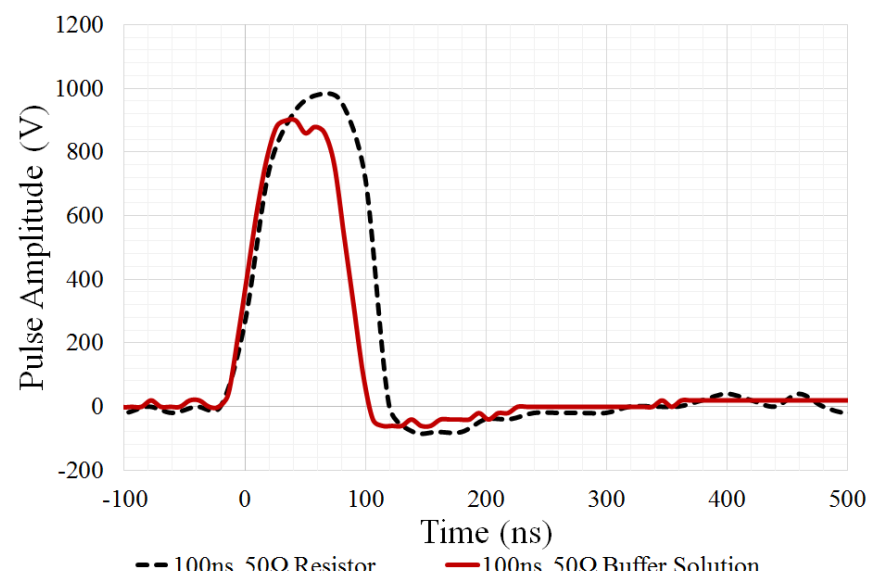

(a)

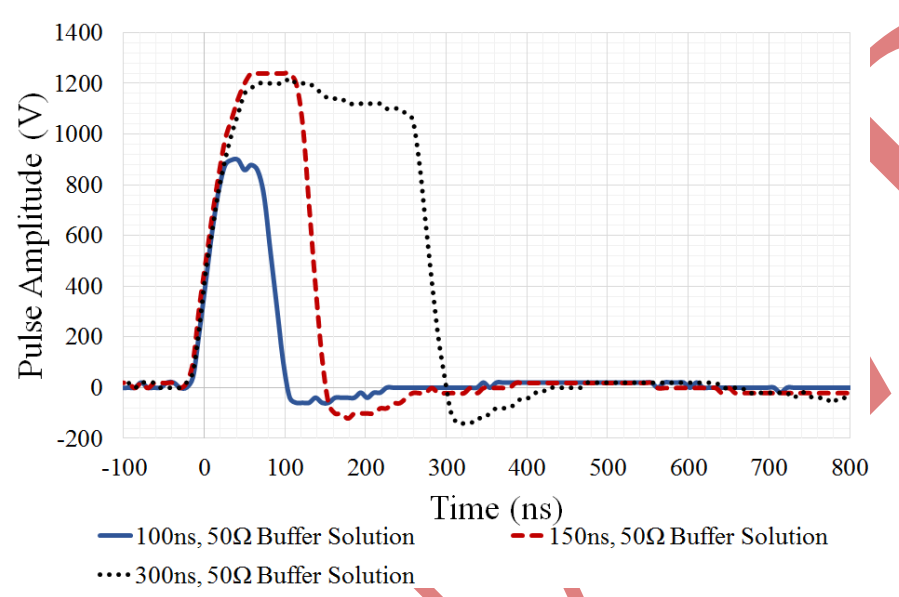

Figure 8. Measured nanosecond pulsed electric fields applied to various loads. (a) comparison of a single $100 \mathrm{~ns}, 50 \mathrm{~Hz}, 20$ pulses with a $50 \Omega$ resistor load (black dashed line) and $50 \Omega$ buffer solution with D283 cell line load (solid red line). (b) comparison of a single $100 \mathrm{~ns}, 50 \mathrm{~Hz}, 20$ pulses of various widths: 100ns (blue solid line), 150ns (red dashed line) and 300ns (black dotted line) pulse, with a $50 \Omega$ buffer solution with D283 cell line load.

Figure 8 a suggests that the buffer load is $50 \Omega$, because the measured waveform of the applied 100ns pulsed electric field with the artificial buffer solution (red solid line) is comparable to the waveform measured with a $50 \Omega$ resistor (black dashed line) as a load. It can be seen that the presence of the D283 cells did not affect the electrical properties of the buffer solution medium since cells represent an extremely small fraction of the global solution volume contained within the cuvette. Therefore, the artificial $50 \Omega$ buffer solution can effectively represent a $50 \Omega$ load from an electrical point of view.
Figure $8 \mathrm{~b}$ depicts the 100ns (blue solid line), 150ns (red dashed line) and 300ns (black dotted line) voltage pulse waveforms measured across the electroporation cuvette containing D283 MB cell line suspended with the $50 \Omega, 0.3 \mathrm{~S} / \mathrm{m}$ buffer solution. These waveforms illustrate the electrical signal delivered to the cells during the biological investigations (permeabilization and viability tests). The cells were exposed to a symmetrical voltage pulse with a maximum amplitude of $\sim 1.2 \mathrm{MV} / \mathrm{m}$, which are similar to the results obtained in simulations, as shown in Figure $4 a$.

The waveforms in Figure $8 \mathrm{~b}$ demonstrates that the 100ns, 150ns and 300ns pulses applied to the D283 MB cell line are, square and symmetrical, with minimal overshoot and ringing.

\section{B. Permeabilization tests}

For the permeabilization tests D283 cells were grown in a humidified atmosphere at $3{ }^{\circ} \mathrm{C}$ and $5 \% \quad \mathrm{CO}_{2}$ in $\mathrm{MEM}$ supplemented with $10 \%$ fetal bovine serum and $1 \%$ of penicillin streptomycin. Cells were scraped, centrifuged and suspended in the artificial $50 \Omega$ buffer, and then YO-PRO-1 $(3 \mu \mathrm{M})$ was added 5 minutes before the electric pulses delivery.

To test cell permeabilization, pulses were delivered according to the protocol as reported in Table 5. A non-pulsed sample was also included in the analysis.

Table 5. Cell population permeabilization rate following electric field exposure.

\begin{tabular}{|c|c|c|c|c|}
\hline $\begin{array}{c}\text { Pulse } \\
\text { Width } \\
(\mathrm{ns})\end{array}$ & $\begin{array}{c}\text { E-field } \\
\text { Strength } \\
(\mathrm{MV} / \mathrm{m})\end{array}$ & $\begin{array}{c}\text { Number } \\
\text { of Pulses }\end{array}$ & $\begin{array}{c}\text { Repetition } \\
\text { Frequency } \\
(\mathrm{Hz})\end{array}$ & $\begin{array}{c}\text { Permeabilization } \\
\text { Rate }(\%)\end{array}$ \\
\hline 100 & $\sim 0.9$ & 1 & 1 & 5 \\
\hline 100 & $\sim 0.9$ & 20 & 1 & 5 \\
\hline 200 & $\sim 1.2$ & 1 & 1 & 5 \\
\hline 200 & $\sim 1.2$ & 20 & 1 & 18 \\
\hline 300 & $\sim 1.2$ & 1 & 1 & 90 \\
\hline 300 & $\sim 1.2$ & 20 & 1 & 5 \\
\hline 0 & 0 & 0 & 0 & \\
\hline
\end{tabular}




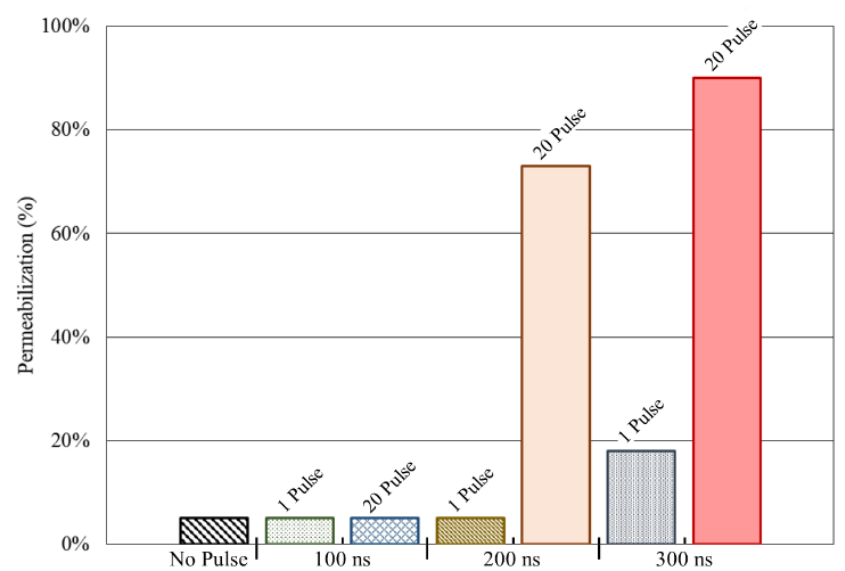

(a)

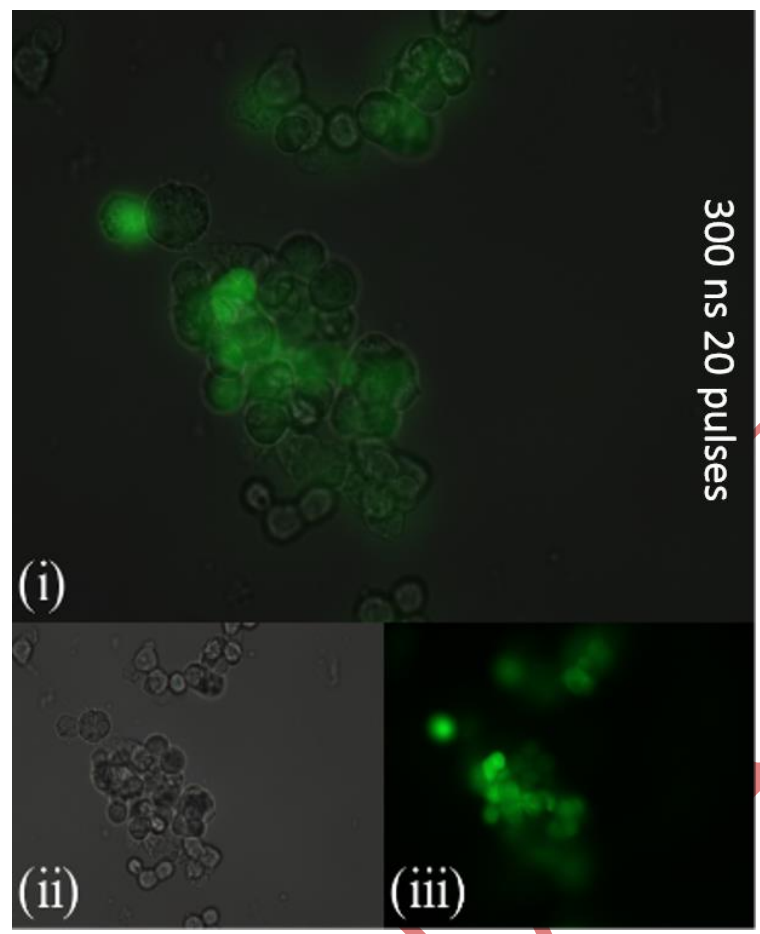

(b)

Figure 9 (a) D283 permeabilization rate following exposure to electric pulses with various pulse parameters. (b) YO-PRO-1 uptake after exposure to 20 pulses of $300 \mathrm{~ns}$ at $1.2 \mathrm{MV} / \mathrm{m}$ : i. bright field superimposed to fluorescence microscope image. ii. bright field images. iii. fluorescence microscope image.

Figure 9a illustrates various permeabilization rates of the D283 cells exposed with different pulse protocols in terms of pulse width, and number of pulses. The same figure indicates that exposing D283 cells to 200ns and 300ns signals with 20 consecutive pulses resulted in more than $70 \%$ and $90 \%$ of permeabilized cells respectively. This is further confirmed by observing Figure 9b where images of permeabilized D283 are shown. For the same sample, the bright field image is also presented (Figure 9bii) to demonstrate the presence of D283 cells in the reviewed sample.
Electropermeabilized cells were observed under fluorescence microscopy (YO-PRO-1 wavelength emission $=510 \mathrm{~nm}$ ), and percent of permeabilization is computed as the ratio of fluorescent cells over the total imaged D283 cells, in three different observation areas.

\section{Viability test}

To assess cell viability, the well-established trypan blue exclusion test was performed. D283 cells were scraped and suspended in the artificial $50 \Omega$ buffer. Then the cells were electropermeabilized using the pulses protocol in Table 5.

Viability was evaluated immediately after the pulse delivery and at 24 and 48 hours after the electric treatment. Specifically, $10 \mu \mathrm{L}$ of trypan blue was added to the $10 \mu \mathrm{L}$ of cell solution. Live cells were automatically counted using a commercial system (Luna II by Logos) in disposable counting chambers.

In Figure 10 viability is expressed as the percentage ratio of the pulsed sample over the control (non-pulsed sample). These data show a high cell viability when $100 \mathrm{~ns}$ and $200 \mathrm{~ns}$ are applied. When $300 \mathrm{~ns}$ pulses are delivered to cells, viability of cells is reduced especially when 20 consecutive pulses of $300 \mathrm{~ns}$ are applied (see viability after 24 and 48 hours from exposure).

Bright field images after 48 hours from the exposure are reported in Figure 10. These images confirm that D283 cells exposed to $100 \mathrm{~ns}$ and $200 \mathrm{~ns}$ are slightly affected by electric pulses compared to the non-pulsed (sham) sample. Cell viability and morphology seemed much more degraded when 20 pulses of 300ns durations are delivered.

These observations lead to the hypothesis that D283 start to be irreversibly permeabilized when multiple pulses (20) of 300ns are applied. Fewer pulses (less than 20) seem to act on D283 cell line in a reversible manner. 


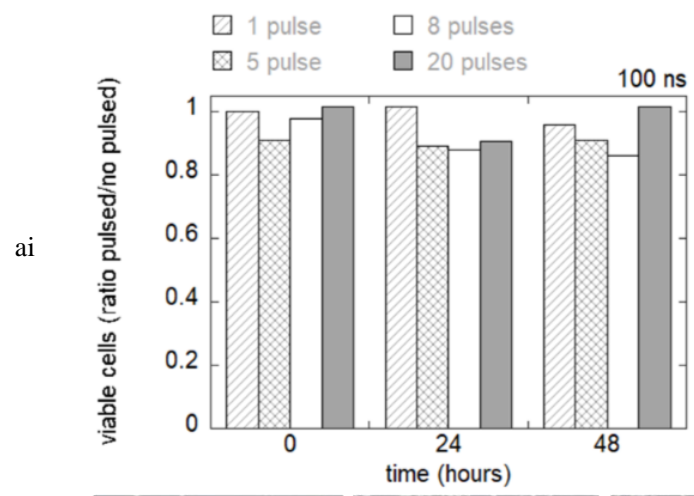

a.ii

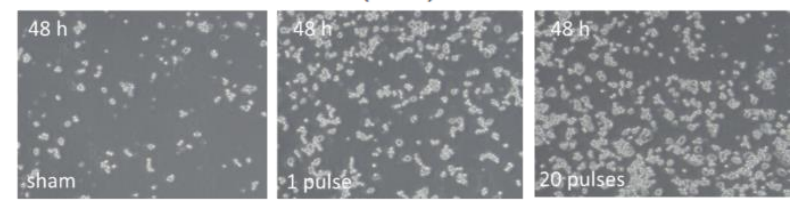

b.i

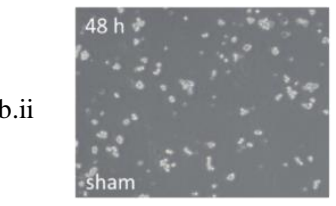

b.ii

c.ii
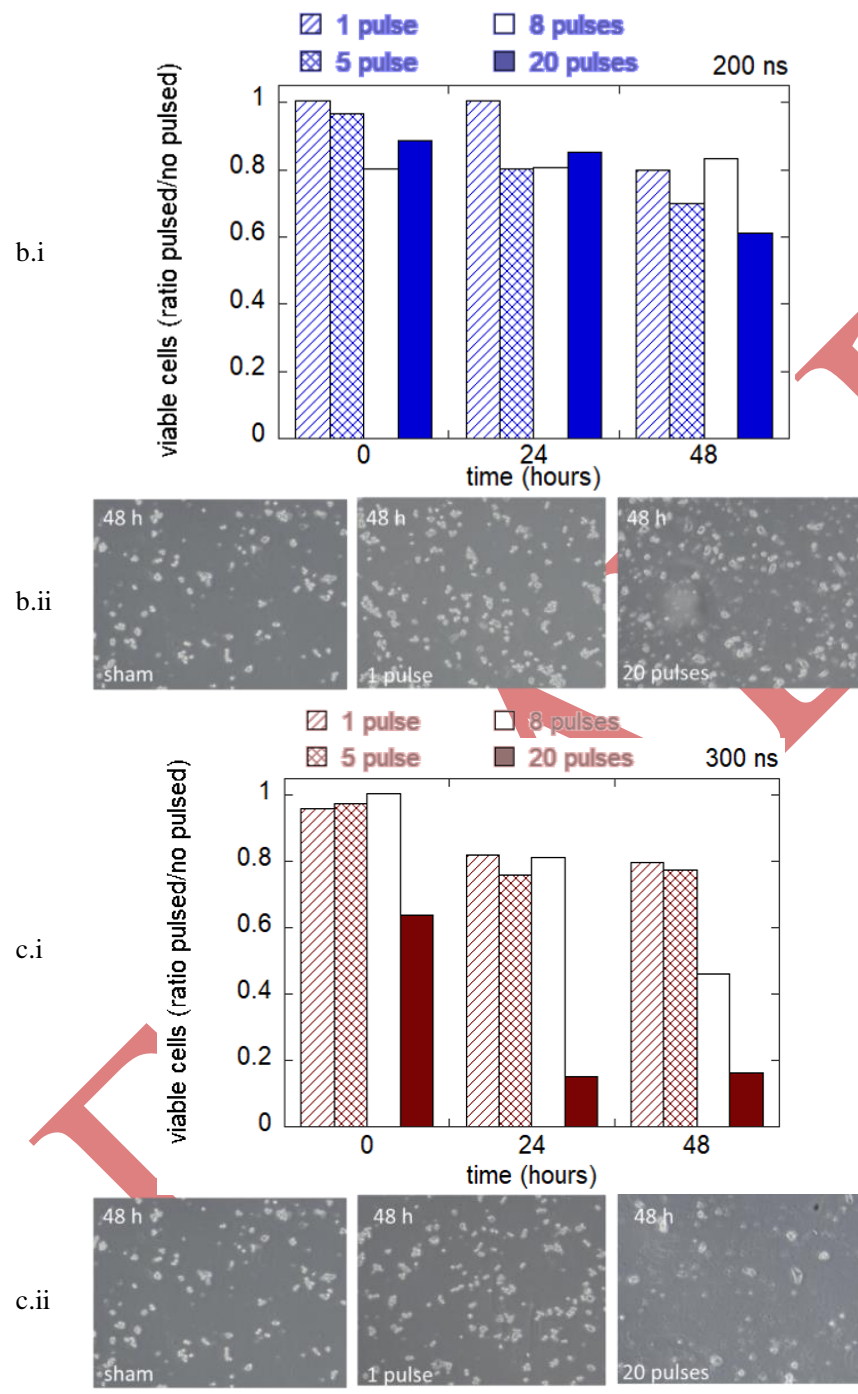

$\square 1$ pulse

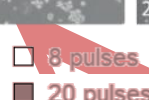

ses
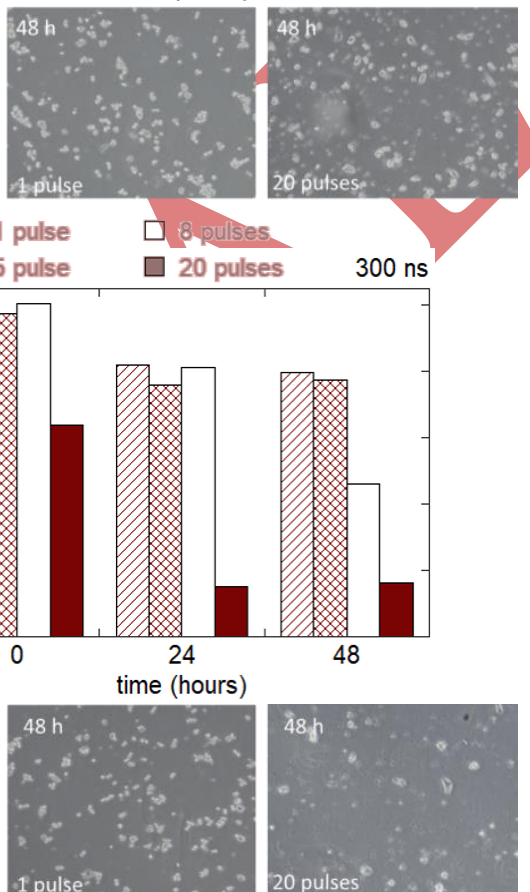

\section{ns}

Figure 10 (i) Result of viability test in panel (ii) bright field images after 48 hours from the electric field exposure of width: (a) 100ns (b) 200ns (c) 300ns.

\section{Non-thermal effect}

The short duration (nanoseconds) and low repetition frequency $(1 \mathrm{~Hz})$ of the electric pulses ensure that the energy delivered into the biological system should be nonthermal [54-55]. A nonthermal approach of neutralising CSCs is an appealing treatment approach since it could allow for a targeted neutralization of a tumour without heating the cells above body temperature. This would result in predominantly sparing healthy cells, extracellular matrix, nearby vessels and structures while allowing tissue regrowth and preventing unwanted damage to patient brain tissue $[1,54-55]$.

To verify that the delivered electric protocols resulted in a nonthermal effect, as literature suggests $[1,50-51]$, a cuvette heating analysis using specific heat capacity equation has been conducted.

The estimated temperature rise per pulse, $\Delta \mathrm{T}$ (3), and the maximum mean rate of temperature rise, $\Delta \mathrm{T}_{\max }$ (4) where calculated using the applied nanosecond pulsed electric field parameters (pulse width, pulse amplitude, number of pulses) and biological load parameters.

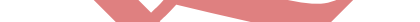

$$
\begin{gathered}
\Delta T=\frac{E}{c m}=\frac{\left(\frac{V^{2}}{Z} P_{w}\right)}{c(\rho v o l)} \\
\Delta \mathrm{T}_{\max }=\frac{E}{c m} N=\frac{\left(\frac{V^{2}}{Z} P_{w}\right)}{c(\rho v o l)} N
\end{gathered}
$$

In equations (3) and (4), E is the heated energy (Joules, J) due to the applied nanosecond pulsed electric field parameters. E, depends on $\mathrm{V}$, the applied pulse amplitude (Volts), $\mathrm{Z}$ is the impedance of the biological load $(\Omega), \mathrm{P}_{\mathrm{w}}$ is the pulse width/duration of the applied electric pulse (seconds, $s$ ). $\mathrm{c}$ is the specific heat capacity $\left(\mathrm{J} / \mathrm{Kg}{ }^{\circ} \mathrm{C}\right)$ and $\mathrm{m}$ is the mass $(\mathrm{Kg})$ of the biological load. $\mathrm{m}$ is determined by the density, $\rho\left(\mathrm{kg} / \mathrm{m}^{3}\right)$, and the total volume, $\operatorname{vol}\left(\mathrm{m}^{3}\right)$ of the biological load. In equation (4), $\mathrm{N}$ is the number of pulses delivered to the buffer solution.

The biological load consists of an impedance of $50 \Omega$ (as shown) and a specific heat capacity of $4.18 \mathrm{~J} / \mathrm{g} /{ }^{\circ} \mathrm{C}$, the same heat coefficient value as water, because the buffer solution consists mainly of water. In addition to having the same specific heat capacity as water, the buffer solution also has the same density as water $\left(\sim 1000 \mathrm{~kg} / \mathrm{m}^{3}\right)$. The total volume of liquid (buffer solution/biological load) the cuvette can occupy is $55 \times 10^{-9} \mathrm{~m}^{3}$ (as the dimension of the cuvette is $1 \mathrm{~mm} \times 5 \mathrm{~mm} \times 11 \mathrm{~mm}$ ).

As the D283 cell line consists of a small fraction of the global solution volume it can be assumed that the heating effect on the cell solution is the same as the heating effect on the simple buffer solution. 
Table 6 shows the estimated temperature rise per pulse and the maximum mean rate of temperature rise the $50 \Omega$ buffer solution experienced with various pulse parameters (amplitude, pulse width and frequency).

Table 6. Heating effect of applied nanosecond pulsed electric field on the buffer solution.

\begin{tabular}{|c|c|c|c|c|}
\hline $\begin{array}{c}\text { Pulse } \\
\text { Width (ns) }\end{array}$ & $\begin{array}{c}\text { Pulse } \\
\text { Amplitude (V) }\end{array}$ & $\begin{array}{c}\text { Number } \\
\text { of pulses } \\
(\mathrm{N})\end{array}$ & $\begin{array}{c}\Delta \mathrm{T}(\mathrm{mK} \text { or } \\
\left.\mathrm{m}^{\circ} \mathrm{C} \text { per pulse }\right)\end{array}$ & $\begin{array}{c}\Delta \mathrm{T}_{\max } \\
(\mathrm{K} / \mathrm{s}) \text { or } \\
\left({ }^{\circ} \mathrm{C} / \mathrm{s}\right)\end{array}$ \\
\hline 100 & 900 & 1 & 7.04 & 0.007 \\
\hline 100 & 900 & 20 & 7.04 & 0.141 \\
\hline 200 & 1200 & 1 & 25.02 & 0.025 \\
\hline 200 & 1200 & 20 & 25.02 & 0.500 \\
\hline 300 & 1200 & 1 & 37.53 & 0.038 \\
\hline 300 & 1200 & 20 & 37.53 & 0.751 \\
\hline
\end{tabular}

This theoretical thermal investigation clearly indicates that the change in the temperature of the biological load is dependent on the pulse properties. Properties such as: pulse width, pulse amplitude, and repetition frequency (maximum mean rate of temperature rise). Our computation highlights that the short duration and low repetition frequency of electric field pulses delivers non-thermal energy into the buffer solution and therefore the D283 cells [1,54-55]. Table 6 indicates that the maximum temperature rise the cells experience within the cuvette is $37.53 \mathrm{mK}$ or $\mathrm{m}^{\circ} \mathrm{C}$, with a potential of rising by $1.876 \mathrm{mK}$ or $\mathrm{m}^{\circ} \mathrm{C}$ in a second, assuming that no heat is dissipated away from the surrounding environment (air, material, equipment etc).

The cuvette is designed to have an impedance of $50 \Omega$ in order to absorb all of the incident power. The voltage across the load is $900 \mathrm{~V}$ peak for a duration of $100 \mathrm{~ns}$. This has a peak power of $16.2 \mathrm{~kW}$, which only depends on the voltage and the impedance. If $16.2 \mathrm{~kW}$ is delivered to the cuvette for $100 \mathrm{~ns}$ then this is equivalent to $2 \mathrm{~mJ}$ of energy. The volume of fluid in the cuvette is $55 \mathrm{ml}$. The $1.6 \mathrm{~mJ}$ energy delivery will increase the temperature of $5.5 \mathrm{ml}$ of water by $7.0 \mathrm{mK}$.

Assuming that the pulse heats only the fluid, and not the walls of the cuvette, the heat will escape from the fluid in the cuvette through the walls. The surface area of the walls is $142 \mathrm{~mm}^{2}$. Perspex has a thermal conductivity of $0.21 \mathrm{~W} / \mathrm{m} / \mathrm{K}$. A temperature gradient of $0.07 \mathrm{~K} / \mathrm{mm}$ would carry away all the heat from one pulse through the walls in a second. If the thickness of the walls is $5 \mathrm{~mm}$ then there would be about a third of a degree Kelvin across the walls.

None of the fluid in the cuvette is more than $0.5 \mathrm{~mm}$ from a wall, so heat transfer from the centre of the fluid to the walls should be at least as quick as through the cuvette walls and should not result in a large temperature rise.
The temperature in the centre of the fluid in the cuvette is unlikely to rise more than one degree Kelvin, and this depends to a large extent on the heat transfer from the cuvette to its surroundings, which is affected by such things as the material of the holding brackets, the contact area and pressure, and the amount of movement in the surrounding air.

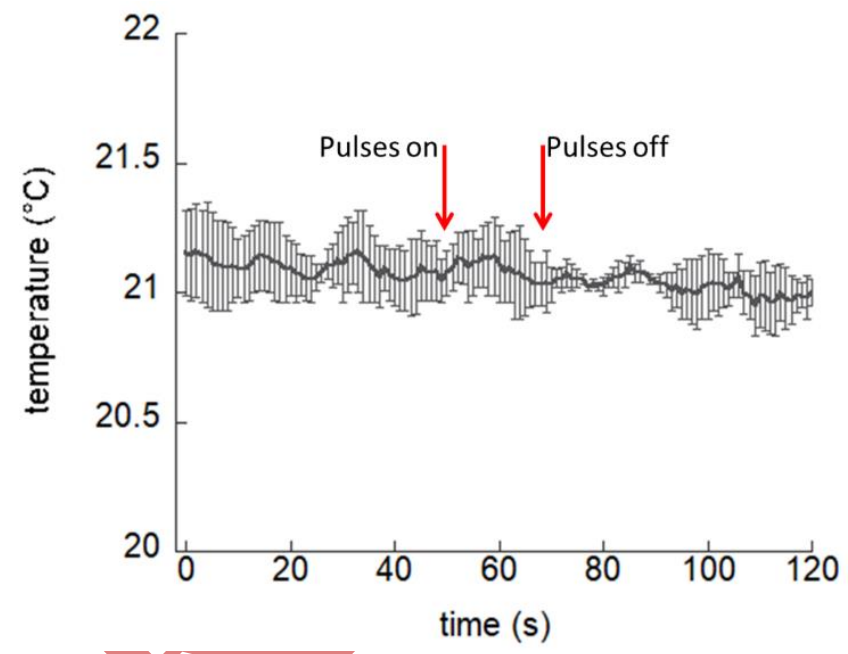

Figure 11. Temperature trend within the electroporation cuvette electrodes before and after the electric pulses delivery. Bars represent standard deviation of the measurements over three independent acquisitions.

To further demonstrate absence of thermal effects, the temperature of the buffer contained in the electroporation cuvette was measured using a fiber optic probe (LumaSense OEM Modules, optic fiber dimensions $0.3 \mathrm{~mm}$ ) directly placed between the electrodes before (1min), during and after (1min) the exposure. The strongest exposure condition employed in bio-experiments $(300 \mathrm{~ns}, 20$ pulses at $1 \mathrm{~Hz})$ was considered for this test. No macroscopic temperature increase is observed, as shown in Figure 11. Therefore, due to the very small temperature rise computed numerically, which is even macroscopically not detectable at experimental level, multiphysics numerical simulations to accurately determine the temperature rise of the fluid in the cuvette were forfeited.

\section{CONCLUSION}

A nanosecond electric field pulse generator has been designed and fully characterized from a pulse amplitude, pulse duration and repetition rate into a range of load impedances. It has also been characterised in terms of its biological efficacy.

The designed generator has proven to be a very useful instrument for biologist to carry out a range experiments on cells. The ability to vary the pulse width, repetition frequency, number of pulses and amplitude is a key feature for such application. This versatile generator is attractive to biologists, since it supports a wide range of pulse protocols to define optimal electric parameters for cell neutralization. Additionally, due to the use of conventional and non-specialist components 
this generator is a very cost-effective solution in comparison to pulsed electric field generators that are currently commercially available.

The generator is well matched to the applicators (cuvette with $50 \Omega$ buffer solution and cuvette holder); delivering square (flattop) electric field pulses with minimal ringing and overshoot.

The overall system including the generator, the cuvette housing unit, and buffer solution resulted in successful permeabilization of D283 cells. More than $70 \%$ of cell population were deemed to be permeabilized when multiple pulses (20) of 200ns or longer pulse width were delivered. A viability study, following permeabilization tests, seems to indicate that D283 starts to be irreversibly permeabilized when multiple pulses (20) of 300ns are delivered. The achieved cell permeabilization is nonthermal even for the stronger exposure condition.

Further perspectives of our work imply technological improvements, as the possibility to deliver different shaped pulse waveforms (e.g. bipolar), as well as introducing an impedance matching network to improve matching strategy between the generator output and the load (cell line, tissue etc). A matching strategy is imperative in future work for a more efficient electric-field distribution of $\sim 1.4 \mathrm{MV} / \mathrm{m}$ at all load impedances. In reality, this aspect is significant for in-vivo and clinical application as biological matter, such as cell-line and tissue etc, are naturally of low impedances, $\sim 10 \Omega$.

The use of smaller dyes, with respect to YO-PRO-1, for detection of cell electropermeabilization is a consideration for future work. Indeed, one interesting possibility is the transport of small ions as $\mathrm{Ca}$, through the uptake of specific markers as Fluo4 [56]. Recent study suggested verification of eventual microthermal heating at cell level, looking at the fluoresce of the Rhodamine B dye [54].

The vision is for the designed nanosecond pulsed electric field generator to achieve targeted non-thermal neutralization of $\mathrm{MB}$ CSCs supporting both in-vitro and in-vivo test, while supporting further nanosecond-pulse-based applications in biology, medicine and/or biotechnology in a cost-effective manner.

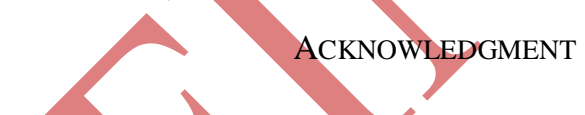

The authors thanks the European Union's Horizon 2020 research and innovation program under grant agreement No.737164, SUMCASTEC, for the received funding. The authors would like to thank partners of the SUMCASTEC project for the successful collaboration. Authors acknowledge B. Tanno from ENEA for the support in cell culturing and microscopy.

\section{REFERENCES}

[1] R. Sundararajan, Electroporation-based therapies for cancer from basics to clinical applications. Waltham, MA: Woodhead Pub, 2014.
[2] A. Silve, R. Vezinet and L. Mir, "Nanosecond-Duration Electric Pulse Delivery In Vitro and In Vivo: Experimental Considerations", IEEE Transactions on Instrumentation and Measurement, vol. 61, no. 7, pp. 19451954, 2012.

[3] "General Optimization Guide for Electroporation", Btxonline.com, 2018. [Online]. Available: https://www.btxonline.com/media/wysiwyg/education_page/Electroporation\% 20Optimization\%20Guide.pdf.

[4] J. Weaver, "Electroporation of cells and tissues", IEEE Transactions on Plasma Science, vol. 28, no. 1, pp. 24-33, 2000.

[5] J.F. Edd, L. Horowitz, R.V. Davalos, L.M. Mir and B. Rubinsky, "In Vivo Results of a New Focal Tissue Ablation Technique: Irreversible Electroporation", IEEE Transactions on Biomedical Engineering, vol. 53, no. 5, pp. 1409-1415, 2006.

[6] T. Kotnik, P. Kramar, G. Pucihar, D. Miklavčič and M.Tarek, "Cell Membrane Electroporation - Part 1: The Phenomenon", IEEE Electrical Insulation Magazine, vol. 28, no. 5, pp. 14-23, 2012.

[7] A. Denzi, C. Merla, L. Caramazza, A. De Angelis, F. Apollonio and M. Liberti, "Microdosimetry in Biomedical Applications: Importance of Realistic Models at the Cellular and Subcellular Levels", EMF-Med 2018 Book of Abstract, pp.40-41, 2018.

[8] C. Consales, C. Merla, B. Benassi, A. Muscat, T. Garcia-Sanchez, C. Marino and L.M. Mir, "Oxidative and Epigenetic Effects of Ultra-short Pulsed electric Fields on Neuronal-like Cells", EMF-Med 2018 Book of Abstract, pp.78-79, 2018.

[9] C. Merla, T. Garcia-Sanchez, A. Muscat, C. Consales, B. Benassi, F.M. Andre, C. Marino, and L.M. Mir, "Nanosecond pulsed electric fields modulate $\mathrm{Ca}^{2+}$ fluxes in SH-SY5Y neuroblastoma cell line", EMF-Med 2018 Book of Abstract, pp.80-81, 2018.

[10] S. Botha, B. Lopez, A. Muscat, Ó. Lucía, H. Sarnago, A. Naval, J.M. Burdio, T. García-Sánchez, L.M. Mir \& F. Andre, "Long term control of cytosolic calcium oscillations in Mesenchymal Stem Cells using repeated electric pulses", EMF-Med 2018 Book of Abstract, pp.83-84, 2018.

[11] K. Schoenbach, R. Nuccitelli and S. Beebe, "Zap", IEEE Spectrum, vol. 43 , no. 8 , pp. $20-26,2006$.

[12] R. Nuccitelli, U. Pliquett, X. Chen, W. Ford, R. James Swanson, S.Beebe, J. Kolb and K. Schoenbach, "Nanosecond pulsed electric fields cause melanomas to self-destruct", Biochemical and Biophysical Research Communications, vol. 343, no. 2, pp. 351-360, 2006.

[13] Schoenbach, K., Hargrave, B., Joshi, R., Kolb, J., Nuccitelli, R., Osgood, C., Pakhomov, A., Stacey, M., Swanson, R., White, J., Xiao, S., Zhang, J., Beebe, S., Blackmore, P. and Buescher, E. (2007). Bioelectric Effects of Intense Nanosecond Pulses. IEEE Transactions on Dielectrics and Electrical Insulation, 14(5), pp.1088-1109.

[14] R. J. Swanson et al., "Melanoma Morphology Change \& Apoptosis Induced by Multiple Nanosecond Pulsed Electric Fields," 2007 International Conference on Electromagnetics in Advanced Applications, Torino, 2007, pp. 1036-1039.

[15] J. Skeate, D. Da Silva, E. Chavez-Juan, S. Anand, R. Nuccitelli and W. Kast, "Nano-Pulse Stimulation induces immunogenic cell death in human papillomavirus-transformed tumors and initiates an adaptive immune response", PLOS ONE, vol. 13, no. 1, p. e0191311, 2018.

[16] R. Nuccitelli, M. Kreis, B. Athos, K. Lui, C. Berridge, P. Nuccitelli and E. Epstein, "PPPS-2013: Nanoelectroablation for human carcinoma therapy", in 
IEEE International Conference on Plasma Science (ICOPS), San Francisco, CA, USA, 2013, p. 1.

[17] P. Krishnaswamy, A. Kuthi, P. Vernier and M. Gundersen, "Compact Subnanosecond Pulse Generator Using Avalanche Transistors for Cell Electroperturbation Studies", IEEE Transactions on Dielectrics and Electrical Insulation, vol. 14, no. 4, pp. 873-877, 2007.

[18] I. W. Davies, C. Merla, A. Zambott, J. Bishop, C. Palego and C. P. Hancock, "Electropermeabilization of Isolated Cancer Stem Cells with a Novel and Versatile Nanosecond Pulse Generator," 2018 IEEE International Microwave Biomedical Conference (IMBioC), Philadelphia, PA, 2018, pp. 106108. doi: 10.1109/IMBIOC.2018.8428941

[19] Cancer Research UK, Cancerreasearchuk.org, 2018. [Online]. Available: http://www.cancerreasearchuk.org

[20] "Brain Tumor: Statistics | Cancer.Net", Cancer.Net, 2018. [Online]. Available: https://www.cancer.net/cancer-types/brain-tumor/statistics

[21] "Brain tumor prognosis | The Brain Tumor Charity", Thebraintumourcharity.org, 2018. [Online]. Available: www.thebraintumourcharity.org

[22] "Cardiff University", Cardiff University, 2018. [Online]. Available: https://www.cardiff.ac.uk/cancer-stem-cell/research/about-cancer-stem-cells

[23] "The Stem Cell Theory of Cancer | Ludwig Center | Stanford Medicine", Med.stanford.edu, 2018. [Online]. Available: https://med.stanford.edu/ludwigcenter/overview/theory.html

[24] "MicroPulserTM Electroporator | Life Science Research | Bio-Rad", Biorad.com, 2018. [Online]. Available: http://www.bio-rad.com/enuk/product/micropulser-electroporator?ID=83527990-34fb-4b33-b955ca53b57bf8b9

[25] "Electroporators | VWR", Uk.vwr.com, 2018. [Online]. Available: https://uk.vwr.com/store/product/2993634/electroporators

[26] "BTX'М ECM"M 399 Exponential Decay Wave Electroporator", Fisher Scientific, 2018. [Online]. Available: https://www.fishersci.be/shop/products/btx-harvard-apparatus-ecm-399exponential-decay-wave-electroporator/15427220

[27] "FID GmbH - Products - FPG-N Series - Nanosecond High Voltage Pulsers", Fidtechnology.com, 2018. [Online]. Available: http://www.fidtechnology.com/products/fpg-nanosecond.html.

[28] "High Voltage Pulse Generators \& Pulsers | Directed Energy", Directedenergy.com, 2018. [Online]. Available: https://directedenergy.com/high-voltage-pulsers/.

[29] "Avtech Electrosystems Ltd,", Avtechpulse.com, 2018. [Online]. Available: http://www.avtechpulse.com/?gclid=EAIaIQobChMIeagoo3e3gIVBbftCh0AgwzSEAAYAiAAEgIJHPD_BwE.

[30] M. Inc., "High Voltage Power Supplies | Matsusada Precision Inc.", Matsusada.com, $2018 . \quad$ [Online]. Available: https://www.matsusada.com/lp/psel/hvps.html?gclid=EAIaIQobChMIeagoo3e3gIVBbftCh0AgwzSEAAYASAAEgJBo_D_BwE.

[31] Gong, C., Valduga, J., Chateau, A., Richard, M., Pellegrini-Moïse, N., Barberi-Heyob, M., ... Boura, C. (2018). Stimulation of medulloblastoma stem cells differentiation by a peptidomimetic targeting neuropilin-1. Oncotarget, 9(20), 15312-15325. doi:10.18632/oncotarget.24521
[32] "Google Scholar", Scholar.google.co.uk, 2019. [Online]. Available: https://scholar.google.co.uk/scholar?q=nanosecond+high+voltage+pulse+gene rator+electroporation\&hl=en\&as_sdt=0\%2C5\&as_ylo=2017\&as_yhi $=2020$.

[33] M. Behrend, A. Kuthi, Xianyue Gu, P. Vernier, L. Marcu, C. Craft and M. Gundersen, "Pulse generators for pulsed electric field exposure of biological cells and tissues", IEEE Transactions on Dielectrics and Electrical Insulation, vol. 10 , no. 5 , pp. 820-825, 2003.

[34] A. Kuthi, P. Gabrielsson, M. Behrend, P. Vernier and M. Gundersen, "Nanosecond pulse Generator using fast recovery diodes for cell electromanipulation", IEEE Transactions on Plasma Science, vol. 33, no. 4, pp 1192-1197, 2005

[35] P. Wijetunga, X. Gu, T. Vernier, A. Kuthi, M. Behrend and M. A. Gundersen, "Electrical modeling of pulsed power systems for biomedical applications," Digest of Technical Papers. PPC-2003. 14th IEEE International Pulsed Power Conference (IEEE Cat. No.03CH37472), Dallas, TX, USA, 2003 pp. 423-428 Vol.1.

[36] J. Sanders, A. Kuthi, Y. Wu, P. Vernier and M. Gundersen, "A linear, single-stage, nanosecond pulse generator for delivering intense electric fields to biological loads", IEEE Transactions on Dielectrics and Electrical Insulation, vol. 16, no. 4, pp. 1048-1054, 2009.

[37] V. Novickij, A. Grainys, P. Butkus, S. Tolvaišienè, J. Švedienè, A. Paškevičius and J. Novickij, "High-frequency submicrosecond electroporator", Biotechnology \& Biotechnological Equipment, vol. 30, no. 3, pp. 607-613, 2016

[38] M. Reberšek and D. Miklavčič, "Advantages and Disadvantages of Different Concepts of Electroporation Pulse Generation", Automatika, vol. 52, no. 1, pp. 12-19, 2011.

[39] C2M1000170D, Silicon Carbide Power MOSFET C2M MOSFET Technology. N-Channel Enhancement Mode. Cree, 2015, pp. 1-11.

[40] "GT40WR21, Silicon N-Channel IGBT", TOSHIBA, 2018 [Online]. Available:

online.com/webdocs/1436/0900766b81436c34.pdf https://docs-emea.rs-

[41] "TSC5802D, High Voltage Fast-Switching NPN Power Transistor", Taiwan Semiconductor, 2018 [Online]. Available: https://docs-emea.rsonline.com/webdocs/1445/0900766b81445ef6.pdf

[42] TLP352, TLP352F Photocouplers, GaAlAs Infrared LED \& Photo IC. TOSHIBA, 2011, pp. 1-21.

[43] R. Boylestad, L. Nashelsky and L. Li, Electronic devices and circuit theory, 7th ed. New Jersey: Prentice Hall, 1998.

[44] R. Severns, Siliconix power application handbook, Siliconix incorporated, Santa Clara, California, 1985.

[45] Kogure, H., Kobayashi, H., Takahashi, Y., Myono, T., Sato, H., Kimura, Y., ONAYA, Y. and Tanaka, K., 2002. Analysis of CMOS ADC nonlinear input capacitance. IEICE transactions on electronics, 85(5), pp.1182-1190.

[46] "C2M1000170D 1000m $\Omega$ 1700-V SiC MOSFET | Wolfspeed", Wolfspeed.com, 2018.2 [Online]. $\quad$ Available: https://www.wolfspeed.com/power/products/sic-mosfets/c2m1000170d.

[47] FS40, FS Series Isolated, proporsional DC to HV DC converters, XPPower, 2011, pp. 1-9.

[48] C. Merla et al., "A 10-\$1Omega\$High-Voltage Nanosecond Pulse Generator," in IEEE Transactions on Microwave Theory and Techniques, vol. 58 , no. 12 , pp. 4079-4085, Dec. 2010 
[49] C. Merla, A. Casciati, M. Tanori, B. Tanno and M. Mancuso, "SUMCASTEC_180123_NA_protocolWP3_protocol_.pdf_Rome_.

Merla_Partners and public_NA", Zenodo, 2018. [Online]. Available: https://zenodo.org/record/1157784\#.Wm9N3a51-po

[50] "Gene Pulser $囚 /$ MicroPulser"M Electroporation Cuvettes, $0.1 \mathrm{~cm}$ gap \#1652089 | Life Science Research | Bio-Rad", Bio-rad.com, 2018. [Online]. Available: http://www.bio-rad.com/en-uk/sku/1652089-gene-pulsermicropulser-electroporation-cuvettes-0-1-cm-gap

[51] Kenaan, M., Amari, S., Silve, A., Merla, C., Mir, L., Couderc, V., ArnaudCormos, D. and Leveque, P. (2011). Characterization of a 50- $\Omega$ Exposure Setup for High-Voltage Nanosecond Pulsed Electric Field Bioexperiments. IEEE Transactions on Biomedical Engineering, 58(1), pp.207-214.

[52] Tektronix , "TDS5000B Series - Digital Phosphor Oscilloscopes Read This First | Tektronix", Tek.com, 2018. [Online]. Available: https://www.tek.com/oscilloscope/tds5054b-manual/tds5000b-series-1

[53] PPE 5 kV. Glasgow: Teledyne LeCroy, 2018, pp. 1-2. [Online]. Available: http://cdn.teledynelecroy.com/files/manuals/ppe_5kv_user_manual.pdf

[54] D. Moreau, C. Lefort, R. Burke, P. Leveque and R. O'Connor, "Rhodamine B as an optical thermometer in cells focally exposed to infrared laser light or nanosecond pulsed electric fields", Biomedical Optics Express, vol. 6, no. 10, p. 4105, 2015.

[55] S. Kohler, R. O'Connor, T. Vu, P. Leveque and D. Arnaud-Cormos, "Experimental Microdosimetry Techniques for Biological Cells Exposed to Nanosecond Pulsed Electric Fields Using Microfluorimetry", IEEE Transactions on Microwave Theory and Techniques, vol. 61, no. 5, pp. 2015 2022, 2013.

[56] T. García-Sánchez, C. Merla, J. Fontaine, A. Muscat and L. Mir, "Sine wave electropermeabilization reveals the frequency-dependent response of the biological membranes", Biochimica et Biophysica Acta (BBA) Biomembranes, vol. 1860, no. 5, pp. 1022-1034, 2018.

I. W. Davies was born in Bodelwyddan, North Wales, UK in 1995. He received a MEng degree in electronic engineering from Bangor University, Bangor, U.K. in 2017.

Since 2017, he has been with Creo Medical Limited, Chepstow, U.K., where he is involved in Research and Development within the Company. His current research includes the development of a nanosecond-duration pulse generators as of the SUMCSTEC project and his current studying for a Ph.D. degree in electronic engineering from Bangor University.

C. Merla (S'06-M'09) received the M.S. and Ph.D. degrees in electronic engineering from the Sapienza University of Rome, Rome, Italy, in 2004 and 2008 , respectively.

From 2008 to 2012, she was a Post-Doctoral Fellow with XLIM, CNRSUniversity of Limoges, Limoges, France, and with the Italian Inter University Center of Electromagnetic Fields and Biosystems, Rome. In 2012, she joined Lehigh University, Bethlehem, PA, USA, as a Research Scientist. She is with the Italian National Agency for New Technologies, Energy, and Sustainable Economic Development, Rome. She was also a Research Scientist with the Vectorology and Anticancer Therapy Laboratory, CNRS UMR 8203, Gustave Roussy, University of Paris-Sud, Université Paris-Saclay, Villejuif, France, where she develops wideband exposure systems for electropulsation in vitro, their integration with nonlinear optical imaging techniques, and electromagnetic modeling of biological cells. She is now working on ultrashort electric pulses effects on cancer stem cells for innovative medical therapies.
A. Casciati has graduated with honors in Biological Sciences in 1998 at the University "La Sapienza", Rome, and obtained the $\mathrm{PhD}$ in Neurosciences in novel experimental approaches on amyotrophic lateral sclerosis in 2004 at the "Università degli studi di Roma Tor Vergata", Rome. After several postdoctoral fellowships (at "Fondazione Santa Lucia, IRCCS, and EMBL), she has a strong experience in molecular and cellular biology using genetically cells and mice modeling human diseases.

In particular, her main research interests is related to neurobiology field, focusing on molecular and cellular mechanisms of cancer and non-cancer diseases. She's currently a permanent position as researcher at ENEA Casaccia in Rome, Italy, Division of Technologies and Methods for Health Protection. She now involved in different European projects. Her main activities includes (1) effects of low-dose ionizing radiation on neurogenesis and microenvironment modifications on the brain hippocampus in in vivo models; (2) neuroinflammation and DNA repair in transgenic mice models; (3) study of oncogenes expression in cancer and neuronal cells models (4) study on ultrashort electric pulses effects on cancer stem cells for new therapeutic approaches.

M. Tanori PhD, is a researcher at ENEA (Italian National Agency for New Technologies, Energy, and Sustainable Economic Development) since 2009. She has a broad expertise in radiation-induced cancer and noncancer effects in mouse models. In particular her research was focused on cellular and molecular events to study effects of radiation during the brain development with particular attention in cerebellum and hippocampus. More recently her interest is pointing towards development of novel therapeutic strategy to radiosensitize medulloblastoma, the most common malignant pediatric brain tumor.

She has participated in several EU research projects and now she is collaborating on ultrashort electric pulses targeting the medulloblastoma stem cells for innovative medical therapies.

A. Zambotti received high school leaving qualification on Industrial Electronics in 1982

From 1985 to 1993, he worked as a Technician of electro-optical infrared systems with Selenia-Alenia Company. In 1993, he joined the Italian National Agency for New Technologies, Energy and Sustainable Economic Development (ENEA) as a Technician, participating in the realization and setup of the Metrological Centre in ENEA's Trisaia Research Centre. Since 2000, he joined the Electromagnetic Compatibility Laboratory in ENEA's Casaccia Research Centre, where he serves as a Laboratory Technician for electromagnetic compatibility an interference measurements and tests according to military an European standards. He also collaborates in research activities on dielectric spectroscopy measurements and antenna and radarcross-section measurements.

M. Mancuso is a senior scientist at ENEA since 2001. She has a strong background in radiobiology, molecular carcinogenesis and toxicology as well as deep knowledge of experimental animal models for chemical- and radiationinduced tumourigenesis, together with a strong experience in histology, electron microscopy, pathology, molecular pathology and molecular biology. She is involved as coordinator or team member in four ongoing EU projects and in several different national projects. Dr. Mancuso is author of about 60 peer reviewed articles and of more than one hundred conference proceedings in peer reviewed international meetings, where she was often invited, as an expert in radiation biology/oncology. 
J. Bishop received the Ph.D. degree in electronic engineering from Bangor University, Bangor, U.K., in 1997.

$\mathrm{He}$ is currently the Director of Concept Energy Systems at Creo Medical Limited and originally developed microwave treatment and measurement systems at MicroOncology Ltd. He has worked as a Senior Systems and DSP Engineer in diverse radio technologies; in 2G-5G communications, RFPA linearization, radio-tracking, and medical microwave treatment. He has previously worked for Intel, PicoChip, Andrew Corp. and Securicor Information Systems.

M. White received an Honours degree in physics from Exeter University, Exeter, U.K., in 1977.

From 1977 to 1983, he was with the Microwave Tube Division, MO Valve Company [part of GEC (UK)], where he developed miniature magnetrons with small magnetic circuits. From 1983 to 2012, he was with the Radar Cross Section (RCS) Department, Thales UK, as a Microwave Engineer, Trials Engineer, and Mathematical Engineer involved with most aspects of RCS measurement, prediction, analysis, and software design (FACETS RCS prediction software), as well as radar, antenna, filter, and signal processing design. For several years, he was Co-Presenter of The RCS Course and The FACETS Training Course to delegates from industry and government agencies. Since 2012, he has been with CreoMedical Limited, Chepstow, U.K., where he has been involved in the design and development of novel medical tools using microwaves.

Mr. White is a Chartered Physicist. He is a member of the Institute of Physics and the Institution of Engineering and Technology (IET).

C. Palego (S'03-M'07-SM'10) received the M.S. degree in electrical engineering from the University of Perugia, Perugia, Italy, in 2003, and the Ph.D. degree in microwave engineering and optoelectronics from the University of Limoges, Limoges, France, in 2007.

Since 2007, he has been a Postdoctoral Research Associate (2007-2010) and Research Scientist at Lehigh. He is currently a Senior Lecturer in smart sensors and instrumentation at Bangor University, Bangor, U.K., and a Visiting Research Scientist at Lehigh University, Bethlehem, PA, USA. His interests include electromagnetic theory, micro/nanotechnology and biomedical research, as well as RF-MEMS for reconfigurable frontends, antenna arrays, and highpower applications.

C. P. Hancock (SM'07) received the Ph.D. degree in electronic engineering from Bangor University, Bangor, U.K., in 1996.

From 1997 to 2002, he was a Senior Microwave Engineer with Gyrus Medical Ltd. In 2003, he founded MicroOnçlogy Ltd. (now Creo Medical Limited), Chepstow, U.K., to develop his ideas based on dynamic impedance-matching techniques and integrated RADAR measurement techniques using Ku-band energy for the treatment of breast tumors. In 2009, he was given a personal Chair with the Medical Microwave Systems Research Group, Bangor University. He is also the Chief Technical Officer (CTO) and founder of Creo Medical Limited. 